\title{
Marginal youth: mapping spatial capability exclusion in Bogota
}

\author{
Fernando Bucheli $\mathbb{B}$
}

Published online: 23 February 2019

(C) The Author(s) 2019

\begin{abstract}
Although the analysis of urban poverty has advanced towards the integration of objective and subjective approaches to assessing urban development, evaluation of quality of life in cities remains tied to a commodity framework which conceptualises it as the mere dotation of urban amenities. Multidimensional indicators of quality of life attempt to overcome this sort of restriction by considering broader informational spaces to assess well-being in cities. The capability approach has gone some way in addressing this as a multidimensional approach, however the interpretation of spatial phenomena has been absent from its application, meaning that the role of space in the configuration of urban poverty has been neglected. Drawing on cross-sectional data, this paper examines a multidimensional measure of urban poverty based on capabilities of young adults in Bogota in order to identify clusters of deprivation and affluence of wellbeing and determine levels of urban segregation based on this type of metric. The result is a spatialised index of capabilities that allow us to assess well-being from a perspective of socio-spatial differences. The findings support the importance of considering spatial
\end{abstract}

F. Bucheli $(\bowtie)$

University of Cambridge, Alison Richard Building 7 West

Road, Cambridge CB3 9DP, UK

e-mail: jfb51@cam.ac.uk

F. Bucheli

Universidad Externado de Colombia, Bogotá, Colombia patterning of capabilities in understanding poverty dynamics in cities. Spatialised capabilities may help to support urban policy design and promote greater understanding of spatial inequalities in cities.

Keywords Capability approach · Young adults · Spatial inequalities - Spatial autocorrelation . Segregation indices

\section{Introduction}

Urban poverty and residential fragmentation as social problems have usually been studied as processes that tend to manifest themselves spatially (Massey 2009; Soja 2009, 2010), in the sense that urban poverty's occurrence is unrelated to the place where it is generated. Urban poverty is understood in this sense as a problem that is contained in the urban space but is not a direct manifestation of it. Lemanski and Marx (2015) point out that the lack of communication between research on the spatiality of places (located mainly in geography) and the research on how and why urban poverty happens (located mainly in the discipline of development studies) has led to the direct consequence that urban dynamics, and particularly urban poverty, are no longer scrutinised from the perspective of their own spatiality. 
In considering urban scholarly research, urban poverty has been codified in different ways. Since the seminal articles of Wratten (1995) and Satterthwaite (2001) on how to conceptualise deprivation in cities, the way we understand urban poverty has changed from being almost exclusively an extension of improving the levels of income per capita to a wider perspective that acknowledges that urban life requires a much more comprehensive agenda, combining material and non-material assets where people' lives are the focus of attention in assessing economic and social progress. Although it is indisputable that the urban agenda has expanded towards objective and subjective dimensions of development (Evans et al. 2016), the essence of urban well-being remains tied to a commodity framework which understands economic growth and neoliberal paraphernalia as mechanisms to alleviate urban poverty. Within this discourse, cities have been described almost exclusively as centres of innovation and economic growth intended to generate trickle down benefits for all kinds of urbanites (Fainstein 2011).

When measuring quality of life and locating urban poverty in city spaces, the normative debate about its definitions becomes relevant, as developing a definition of urban poverty will inevitably determine its form and characteristics. In tackling this issue, this article introduces capability approach (CA) as an evaluative framework to investigate spatial fragmentation in Bogota. The article endeavours to capture the effects of the production of fragmented spaces ${ }^{1}$ by looking at how inequalities and residential segregation are manifested in the space when a multidimensional approach to poverty is considered. Young adults in Bogota are the focus for analysis, a group who are not only one of the subgroups who suffer most disproportionately the effects of poverty and limited opportunities in the context of contemporary cities (Casas-

\footnotetext{
${ }^{1}$ The concept of fragmented spaces is associated with the idea of a 'city of fragments' or the tendency of modern cities towards the development of spaces that are separated or detached from each other (Castells 1977; Graham and Marvin 2001; Landman 2011). Urban fragmentation is conceptualised as "a spatial phenomenon that results from the act of breaking up, breaking off from, or disjointing the pre-existing form and structure of the city and systems of cities" (Burgess 2007, p. 1). When urban fragmentation produces enclaves of poverty and wealth, the results is a process of residential microsegregation as mixed communities are located at the micro level.
}

Casas et al. 2012; Thompson 2017) but also a group lacking an evaluative framework to assess the effects of urban inequalities on their life trajectories from a perspective of human flourishing and advantage.

The paper employs spatial thinking to examine differentials in young adults' well-being and agency across Bogota. It maps the spatial patterning of capabilities in the city at different scale levels, using a composite indicator of capabilities, which aggregates domains of quality of life relevant to young adults using the CA framework (Sen 1979, 1985). The result is a description of young adult poverty as capability deprivation that reveals socio-spatial differences in human advantage in the Bogota landscape. Following this introduction, a literature review is presented describing major spatial theories of justice and alternative normative frameworks to assess wellbeing and human advantage. Data collection is then presented with the distinct geographical scales employed to assess spatial autocorrelation and residential segregation indices. The next section explains the methods used in each analysis. Results are then presented, identifying city areas where a capability driven intervention should be taken into consideration. The final section recapitulates major findings and sets out the discussion of how spatial relations have a capability narrative relevant to young adults' quality of life in Bogota.

\section{Spatial justice and normative thinking in the literature}

The lack of spatiality in monitoring and assessing urban inequality is also evident in debates regarding the conception and interpretation of how justice should be conceived and interpreted. Modern theories of justices tend to be aspatial in the way that informational spaces of human advantage, or metrics of justice, do not fully consider the effects of space on how human relationships are produced. For instance, Mill's utilitarianism or Rawls's justice as fairness theories can be considered aspatial as they conceptualise the spatiality of inequality as a mere 'distribution' problem rather than one that conceives space as a producer of inequality. Merrifield and Swyngedouw (1997) suggest that non-spatial theories of justice can be seen as invariably "devoid of time and space" ( $p$. 3 ), meaning that central arguments to explain justice 
normally depart from the qualities of space as explicative factors of inequality.

Non-spatial theories of justice have been challenged by sociologists and human geographers (Merrifield 1999; Soja 1999; Unwin 2000) who have identified specific qualities of space which explain why societies are unequal. Within the field of geography, the spatiality of inequality becomes organic when relations of domination and oppression take shape in urban processes such as gentrification, urban fragmentation and segregation. Here, space and place become evaluative aspects to identify factors that contribute to explaining not just territorial injustices and uneven geographies that are reproduced under globalisation (Giddens 1990; Castells 2004; Sassen 2013) and capitalist societies (Harvey 1973, 2006), but also to understand specific features of contemporary cities where urban institutions, policies and discourses contribute to reproducing spatial inequality (Soja 2009, 2010). The evaluative aspect of inequality clearly moves beyond a distributional interrogation for social justice towards one that looks first at systematic relations of oppression and dominance (Young 2011). The spatiality of social justice is also examined from the perspective of programme implementation.

Despite these developments, where the concept of spatial inequality is introduced to critically engage in the understanding of how unjust geographies are conceived and produced (Marcuse et al. 2011), the lack of normative thinking is still a distinct feature of theories of justice that do not embrace a set of spatial outcomes that can be used for evaluative proposes. Without applying a normative framework to assess spatial inequality, social processes of human wellbeing and agency may be subject to oversimplification. For Olson and Sayer (2009), the lack of normativity to define what well-being and quality of life means in the context of contemporary cities has becoming symptomatic of the conversations between space and justice.

In this context, attempts to introduce a metric for spatial inequality appear to focus on alternatives that can evoke the spatial dimension of justice rather than reorient or redefine established arguments of justice. Dikeç (2001) proposes the notion of spatial dialectics of injustice to reconcile the tensions between the distributional paradigm of justice and one that includes a normative content to define what human well-being and agency means to justice. Although this contributes directly to understanding how spatiality serves as a framework within which to understand inequalities, this does not really correct the problem of which normative framework should be used for assessing spatial equity.

Many scholars from the discipline of development studies support the idea that social arrangements and development itself should strive to enhance human flourishing through enlarging real freedoms, rather than focusing on the maximisation of income and commodities. This approach is mainly encapsulated in the capability approach (CA) pioneered by Sen (1979, 1985, 1992), which has revitalised much of the discipline of development studies to the point that it is now central in the foundation of the human development paradigm (Haq 1995; Alkire and Deneulin 2009; Fukuda-Parr 2011). The CA serves as a fruitful framework to motivate a multidimensional and normative evaluation of spatial relations.

Capability scholars (Sen and Williams 1982; Stewart and Deneulin 2002; Gasper 2007; Qizilbash 2011) agree that the evaluation of poverty has been notoriously influenced by the normative framework of utility where human progress is analysed exclusively from a perspective of economic growth, or 'primary goods' (Deneulin and Shahani 2009). As an alternative approach, the CA advocates that social progress should be assessed in the space of capabilities or substantive freedoms that people have and have reason to value. The assessment of spatial inequality from the perspective of the normative metric of Sen's approach can focus alternatively on other evaluative spaces to account for advances in human flourishing such as functionings, capabilities and agency. This link between social justice and spatial inequality is recently addressed by Israel and Frenkel's paper (2017) which presents a conceptual framework to operationalise the $\mathrm{CA}$ as a normative argument to understand spatial inequality in different contexts. The reason to use the CA to link both conceptual aspects is based on the idea that capabilities as a metric of spatial justice are more appropriate as evaluations of well-being and agency would not be carried out hypothetically, as Rawls suggests under the idea of the 'original position', but by one's ability to choose and realise a range of opportunities (Abel and Frohlich 2012).

Based on these contributions and the need to move towards a normative approach that focuses on how 
space determines the quality of life of people, this article applies a spatial analysis framework to determine if multidimensional urban poverty is manifested in the space, giving traction to the idea that multidimensional inequality has a spatial dimension to it.

\section{Data and variables}

The article considers the socio-spatial distances of capabilities for young adults in Bogota and assesses whether multidimensional measures of urban poverty exhibit differences with income-driven measurements. The article uses the positionality of young adults to define urban poverty in terms of domains which are fundamental to living a good quality urban life. Here, the definition of quality of urban life is based on a multidimensional composite index which aggregates 10 different dimensions of what is considered a good quality of life in Bogota - the capability index $(\mathrm{CI}) .^{2}$ The classification of urban poverty in Bogota has traditionally used the socioeconomic stratification system ${ }^{3}$ as a proxy of households' ability to pay, which relies mainly on an assessment of the physical state of buildings and which can be notoriously deficient to conceptualise human flourishing. To correct for this, the analysis compares the spatial distribution of $\mathrm{CI}$ in relation to urban poverty based on strata.

Scores of the CI were georeferenced using three different areal scales: 1. Districts, 2. Zonal Planning Units (UPZs), and 3. Blocks. Bogota is divided into 20 urban districts and 111 UPZs. Districts are administrative-political divisions with relative homogeneity

\footnotetext{
$\overline{2}$ The Capability Index is a composite measure of young adults' quality of life in Bogota. It is drawn in domains of quality of life identified directly with young adults from 18 to 28 years using focus group discussions. Exploratory and confirmatory factor techniques were used to reduce data from secondary data domains of quality of life. The design, aggregation and construction of the $\mathrm{CI}$ is presented in detail in a forthcoming article (Bucheli 2018).

3 The 'stratification system' is a socio-economic mechanism that rank dwellings from one to six strata, aiming to focalising subsidies to compute the utility bills tariffs. The system uses a scale from 1 to 6 strata with 1 as the lowest income and 6 as the highest income. The public policy considers that the physical condition (façade, type of floor, roof materials, etc.), location and built environment surrounding dwellings can work as a proxy to identify urban poor (Uribe and Pardo 2006).
}

in terms of geography, culture and economic activity. Each district is divided by several UPZs, which are larger than neighbourhoods and that serve to plan urban development at the zonal level. The smallest spatial unit used were blocks. ${ }^{4}$

For the case of the regression model, scores of capabilities were geocoded using census tracts data available from the $\mathrm{J} 14$ survey. ${ }^{5}$ In the regression model, the dependant variable is the CI. The index is a composite indicator of 10 domains of quality of life of young adults aged between 18 and 28 years old. Independent variables are socioeconomic observations captured in the J14 survey. Independent variables measure different levels of inequality in young adults: percentage male, percentage stratum group, poverty rate, percentage ethnicity (mestizo) and percentage with a Bachelor's degree. The stratum variable measures residential deprivation and calculates the quality of the built environment in each block. The regression coefficient for these variables estimates whether belonging to higher strata renders equal, higher or lower levels of capability scores. For education outcomes, the percentage of young adults without access to secondary education was considered as a proxy for education inequality. The domain of income poverty is represented by quality of air in the neighbourhood. As with other variables in this set, ethnicity and gender variables attempt to capture degrees of inequality in the production of capability scores.

The article uses Bogota's socioeconomic stratification system as an explanatory variable to predict differences on scores of the CI and to compare patterns of segregation based on capabilities and strata. Based on six different strata or groups, houses in Bogota are classified according to the physical conditions and built environment that are present in the residential area. Although strata differentiation is a powerful

\footnotetext{
${ }^{4}$ For each spatial scale, the CI was computed by obtaining an average indicator of capabilities for each areal unit. Cartography was employed to geo-reference each administrative unit using QGIS. Scores of capabilities were joined from the 44 survey to available shapefiles of urban districts, UPZs and blocks from the Capital District's Spatial Data Infrastructure (IDECA).

5 J14 Survey is part of the 2014 District Youth Study and constitutes the most recent data available with relation to socioeconomic characteristics of the young adult population in Bogota.
} 
indicator to capture spatial differentiation, the system often has focalisation errors since families of high economic resources can be classified as low strata households due to the location and external condition of their place of residence. ${ }^{6}$ For the regression model, results need to be interpreted with caution. In the case of mapping segregation patterns, capability scores will contribute to critically compare the results of using focalisation measures based on strata or capabilities. Indeed, it becomes relevant to evaluate other variables that can capture location decisions and that can provide better information about how people are distributed in the urban space. Previously, Aliaga and Álvarez (2010) looked at variables such as education and poverty to analyse whether territorial segregation evolves differently to socioeconomic indicators. This article attempts to expand that analysis by using a place-based approach using capabilities as an evaluative framework to assess the effects of residential segregation on young adults' quality of life.

\section{Methods}

The article is designed to detect the spatial distribution of capabilities and to reveal whether-if there is segregation patterning - it is distributed in the urban structure of Bogota. To answer these questions the article employs three different but interconnected analyses. First, exploratory data analysis (EDA) is put in place with the aim of testing the presence of spatial autocorrelation among scores of the CI for young adults, and to identify and locate similarities/dissimilarities in terms of capability achievement among young adults. The working hypothesis is that the CI exhibits a spatial dependency as observed values in one location depend on the values observed at neighbouring locations. Second, spatial regression is conducted to assess the importance of the spatial

\footnotetext{
${ }^{6}$ In recent years, the stratification policy in Colombia has been strongly criticized (Gallego et al. 2014; Sepulveda et al. 2014; Econometria 2018). The greatest concern has to do with the fact that the system has lost its ability to discriminate, in the way that improvements in housing conditions are not always reflected in an update of the stratum. In addition to this, the stratification system has inclusion and focalization errors, highlighting the case of rich families living in properties classified as stratum one, or cases of hidden poverty, where there are poor families living in high strata (Sepulveda et al. 2014).
}

components as well as the effects of socioeconomic variables in the CI. A central point in this section is to test whether space/location influences the scores in the CI. And third, a battery of segregation indices is calculated to measure residential fragmentation levels based on capabilities of young adults in Bogota. In comparison to measurements of segregation based on ethnicity, income or class, the article uses capability deprivation as a measure of young adult poverty to test the level of residential fragmentation presented in the urban space of Bogota. Here, the residential segregation pattern produced by the stratification system used in Bogota is compared to the segregation pattern produced by capabilities. The existence of differences will reveal the lack of coherence of territorial redistributive policies to tackle multidimensional domains of human flourishing for young adults, while also describing the current pattern of residential fragmentation in the city

Spatial autocorrelation analysis

As part of the EDA, a test of spatial autocorrelation analysis was performed to investigate whether the CI has a spatial pattern across the city or not. Spatial autocorrelation measures the degree of heterogeneity and clustering using both feature locations and feature values at the same time, so results allow the reporting of the extent to which points (scores) cluster or are randomly spread throughout space.

For the case of the CI, spatial autocorrelation measurements contribute to performing hypothesis testing in the sense of whether scores of the index follow a dispersed, clustered or randomly spatial distribution. Moran's $I$ index is a correlation coefficient which tests the degree to which similar (or dissimilar) spatial units are clustered or not. In a context of model specification, a measurement of spatial autocorrelation based on a global Moran's $I$ will identify a positive autocorrelation when values cluster, and a negative autocorrelation when dissimilar values cluster. ${ }^{7}$ Although this statistic is adequate to identify the existence of spatial patterning (what), it

\footnotetext{
7 Values for Moran's I range from 1 (perfect positive spatial autocorrelation) to -1 (perfect negative spatial autocorrelation). Moran's $I=0$ indicates values are random and independent in space.
} 
does not provide the location where the patterning is produced (where).

The analysis uses a local statistic for cluster detection. Based on a decomposition of global Moran's $I$, the article performs an analysis by using local indicators of spatial association (LISA) to localise significant high/lower capability areas and that are not accounted for by chance (Anselin 1995). A local Moran's I was conducted to test significant spatial clustering of similar and dissimilar values using 'hotspots' and 'coldspots' maps. ${ }^{8}$ During the testing of spatial autocorrelation, statistical significance was set at the $99 \%$ confidence level. In order to reduce the likelihood of reporting clustering without this type of patterning from actual spatial distribution-as even with complete spatial randomness (CSR) can be identified a kind of clustering - a Monte Carlo test was carried out of 999 permutations of random datasets (Good 2010).

Spatial autocorrelation measures were calculated for the different geographic units identified. For this section, spatial autocorrelation was calculated using scores of the CI by urban district, UPZs, blocks (points and polygons) as well as for each individual score (points) of the sample. ${ }^{9}$ Spatial weight matrices were calculated for each zone using common spatial conceptualisations such as contiguity weight of first order (queen's case and rook's case contiguity) and distance weight (fixed distance and $k$-nearest neighbours). ${ }^{10}$ By assessing normality of histograms and the connectivity map offered as features by GeoDa, different possible neighbourhood weights for each specific zone were inspected and compared (Fig. 1). Occurrences of islands, or unconnected observations were discarded. The final selection of spatial weight matrices was based on polygon contiguity matrices that show high coefficients of spatial autocorrelation

\footnotetext{
8 A binary relation of cluster and outliers is represented in the map where four different relations are identified: a cluster of high values $(\mathrm{HH})$, a cluster of low values (LL), an outlier of high values surrounded by low values (HL) and an outlier of low values surrounded by high values $(\mathrm{LH})$.

${ }^{9}$ For each scale unit, a spatial weight matrix was created in GeoDa.

10 The polygon contiguity conceptualisation is more effective for this case as it considers that spatial relationships is a function of polygon proximity, meaning that those young adults who share a boundary, spatial integration tends to increase.
}

along with a high level of statistical significance (Voss and Chi 2006). ${ }^{11}$

\section{Spatial regression model}

Statistical analysis is performed to identify the effects of exploratory variables such as gender, age, strata, marital status, dominance of second language and ethnicity to predict values of the CI. A spatial regression was conducted to account for the presence of spatial effects on how capabilities are produced among young adults in Bogota. First, ordinary least square (OLS) estimation was run and results were compared with spatial statistical models, particularly the spatial autoregressive model (SAR) and the spatial error model (SEM).

In standard regression models, one of the assumptions is independence of the observations, where residuals follow a normal distribution with zero average and constant variance. In the case of the spatial linear model, the presence of spatial dependence violates the hypothesis of uncorrelated values. The existence of spatial dependence in the data is likely to bias inferences as spatial data can show correlation in variables and error terms. In other words, if spatial dependence is ignored in the regression model, inferences will not be robust (Haining and Amable 2013). To improve the predictive power of spatial data and to account for spatial effects when spatial dependencies are significant, spatial regression models include an autoregressive coefficient $(\rho)$, that measures levels of spatial dependence, and a weight matrix (W), that specifies the conceptualisation of spatial relationships (Chi and Zhu 2008).

Firstly, an OLS model was estimated for comparison with the spatial autoregressive model (SAR) and the spatial error model (SEM). In the case of SEM, the error model corrects the effects of inefficiency of estimates by adding a spatial error specification to the model. In SAR, model bias is corrected by adding the spatial lag term as an exploratory variable in the model. The decision rule for spatial regression model selection is based on the spatial regression decision process suggested by Anselin and Rey (2014). ${ }^{12}$ The selected regression model is the

\footnotetext{
${ }_{11}$ For each autocorrelation test, a first order queen contiguity was used.

12 The analysis employed the GeoDa regression tool to run the OLS estimation and to check spatial autocorrelation through Moran's $I$ and Lagrange Multiplier (LM) tests as well as to calculate measures of goodness-of-fit in the regression model.
} 

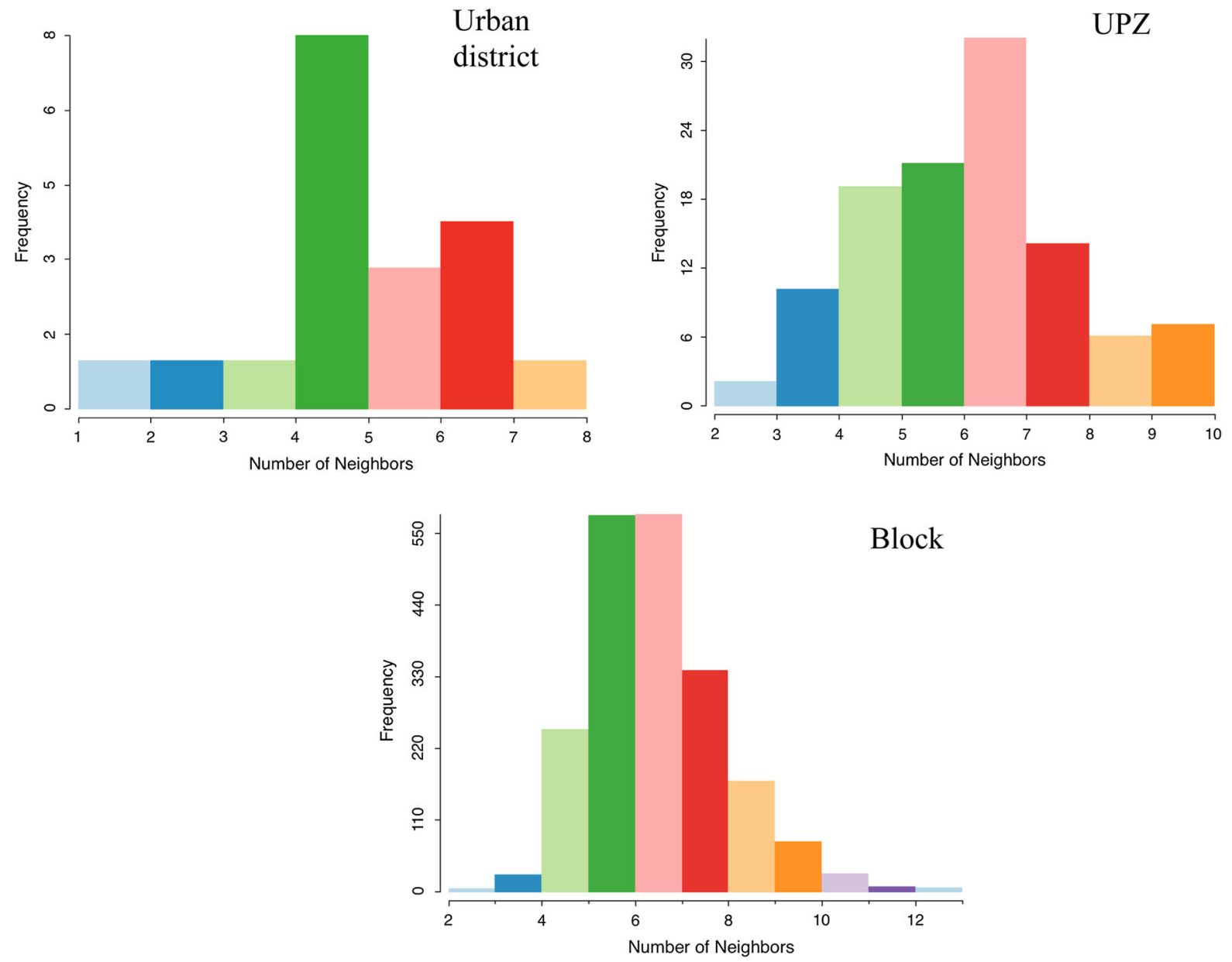

Fig. 1 Connectivity histograms at different administrative scales

one that obtains the best predictive results based on the statistical significance of the spatial autoregressive coefficient, and by comparing the model that obtains the highest log-likelihood and the smallest Akaike info criterion (AIC). The estimation models included are the ordinary least square (OLS) model and the spatial model. The description of the OLS model is:

$C I_{i}=\beta_{0}+\beta_{1} \alpha_{i}+\beta_{2} \theta_{i}+\beta_{3} \vartheta_{i}+\beta_{4} \mu_{i}+\beta_{5} \eta_{i}+u$

where $C I$ is the reported quality of life of individual $i, \alpha$ is gender, $\theta$ is socioeconomic stratum, $\vartheta$ is ethnicity, $\mu$ the quality of air at the neighbourhood level as a proxy for poverty, $\eta$ is school attendance, and $u$ is the error term of individual $i$.
Measures of segregation

Socio-spatial divisions, or the degree to which two or more people live separately from each other, can be quantified by different measures of segregation that account for this feature of disproportionality. Popular measures of segregation include the index of dissimilarity $(D)$, which calculates the evenness with which two different groups are distributed in an aerial unit, or the exposure or interaction index, which captures the sociological aspect of segregation as it measures the probability that a member of a given group interacts with a member of a different group (Reardon and O'Sullivan 2004). For capturing the multidimensional process that urban segregation exhibits, researchers have agreed that five dimensions should be considered to quantify the degree of segregation presented. 
Massey and Denton argue that people can be segregated in a 'variety of ways' (1988, p. 283). For instance, minorities can be overrepresented or underrepresented in certain urban areas (evenness). They can be isolated or integrated in the urban space (exposure). They might be spatially concentrated in terms of the physical space occupied in a given territory (concentration) or can be located close to the urban 'central core' (centralisation). They can also be grouped or dispersed in the urban space (clustering). ${ }^{13}$

Following the argument that urban segregation in Bogota is a multidimensional process, where patterns of segregation tend to move towards a more cellular residential segregation (microsegregation), the quantification of the separation among groups in the city requires the use of different indices to account for the diverse aspects of segregation. This means that an attempt to measure the level of residential fragmentation requires not only an assessment of each of the five dimensions mentioned above but also accounting for the spatial component of the phenomenon. Using scores of the CI, ${ }^{14}$ segregation was measured at urban district, UPZ and block level for different groups of young adults in terms of capability achievement, portraying the spatial distribution of those groups across Bogota, and therefore, identifying the pattern of residential segregation in terms of capabilities. In the case of spatial units, the analysis used 19 urban districts, 99 UPZs and 2042 blocks. Table 1 shows the distribution of population for each spatial unit.

Domains of evenness, exposure, concentration and clustering were measured to assess the level of

\footnotetext{
${ }^{13}$ Evenness and exposure are considered structural dimensions of segregation and are non-spatial indices as they are not sensitive to changes in the size of geographic areas (Wong 1993) — as such, these two dimensions suffer from the checkerboard problem as they do not account for the proximity among groups but only for the composition of the areal unit. Conversely, concentration, centralisation and clustering domains are spatial in nature which means that indices assess the contiguity between centroids to account for interaction among groups.

14 Scores of the CI were classified based on natural breaks (Jenks), where five category groups were created for each areal unit: 'very low', 'low', 'medium', 'high' and 'very high'. These categories were spatialised by joining them with urban district, UPZ and block shapefiles of Bogota, downloaded from the Cadastre of Bogota web page, using QGIS 2.6.1. The created shapefile is uploaded in the open-source software Geo-Segregation Analyzer, where the set of segregation indices are calculated.
}

segregation within the distribution of capabilities of young adults across the urban landscape of Bogota. Table 2 lists spatially and non-spatially segregated indices calculated for each dimension. ${ }^{15}$

\section{Results}

Spatial autocorrelation tests

Figure 2 shows the distribution of the CI based on the natural grouping inherent in the data using the data classification methods of natural breaks (Jenks). ${ }^{16} \mathrm{~A}$ visual examination of the CI suggests that autocorrelation of scores is plausible (Tobler's law) and that the assumption of independent errors between scores might not hold in this case. Autocorrelation seems to be clearer under larger areal units (urban district and UPZ) and less obvious when there is a lower scale (blocks and individual scores).

Tests for autocorrelation at different aggregation levels were positive and significant. Results showed that young adults with high capability scores tend to be located close to other young adults with high capability scores, and places with low capability scores tend to be located close to other disadvantaged areas. This demonstrates that young adults are spatially differentiated in terms of how capabilities are achieved in Bogota. Using local spatial autocorrelation indicators (LISA) it is possible to identify where sorting is located. From the urban district and UPZ perspectives, capabilities are sorted in a clear fragmented and polarised fashion. Figure 3 shows the distribution of significant scores of CI at urban district, UPZ and block levels using LISA indicators.

At district level, there is a positive spatial autocorrelation and significant spatial clustering, Moran's $I=.439, p=0.01, n=19$. The urban districts of Chapinero, Barrios Unidos, Usaquen, Suba and Engativa cluster significantly advantaged young adults

\footnotetext{
15 All indices calculated in this section range from 0 to 1 , where values close to 0 account for low levels of segregation and values close to 1 account for high values of segregation. The selection of indices is based on the criteria of comparability and the potential to compare spatial and no spatial indices across different urban scales.

16 The method classifies the data through class breaks that best group similar values and which maximises the differences between them (Smith et al. 2015).
} 
Table 1 Young adult population groups by level of capability scores

\begin{tabular}{|c|c|c|c|c|c|c|}
\hline \multirow[t]{2}{*}{ Groups } & \multicolumn{2}{|l|}{ Urban locality } & \multicolumn{2}{|l|}{ UPZs } & \multicolumn{2}{|l|}{ Blocks } \\
\hline & Number of people & $\%$ & Number of people & $\%$ & Number of people & $\%$ \\
\hline Very low capabilities & 495 & 6 & 540 & 7 & 440 & 6 \\
\hline Low capabilities & 1322 & 17 & 1404 & 18 & 1375 & 18 \\
\hline Medium capabilities & 2426 & 31 & 2520 & 33 & 2171 & 28 \\
\hline High capabilities & 2436 & 31 & 1987 & 26 & 2082 & 27 \\
\hline Very high capabilities & 1074 & 14 & 1265 & 16 & 1679 & 22 \\
\hline Total population & 7753 & 100 & 7716 & 100 & 7747 & 100 \\
\hline
\end{tabular}

Attrition in the number of people reported in both UPZ and block level are due to missing values that were not georeferenced

Table 2 Selected indices of segregation

\begin{tabular}{|c|c|c|c|c|c|c|c|c|}
\hline \multirow[t]{2}{*}{ Dimension } & \multirow[t]{2}{*}{ Index } & \multirow{2}{*}{$\begin{array}{l}\text { Spatial } \\
\text { nature }\end{array}$} & \multicolumn{3}{|l|}{ Type } & \multicolumn{3}{|l|}{ Level } \\
\hline & & & $\begin{array}{l}\text { One } \\
\text { group }\end{array}$ & $\begin{array}{l}\text { Two } \\
\text { groups }\end{array}$ & $\begin{array}{l}\text { Multi- } \\
\text { group }\end{array}$ & $\begin{array}{l}\text { Urban } \\
\text { locality }\end{array}$ & UPZs & Blocks \\
\hline \multirow[t]{5}{*}{ Evenness } & Index of dissimilarity $(D)$ & $\times$ & $\checkmark$ & $\checkmark$ & $\checkmark$ & $\checkmark$ & $\checkmark$ & $\checkmark$ \\
\hline & Index of dissimilarity adjusted (adj) & $\boldsymbol{V}$ & $\checkmark$ & $\checkmark$ & $\times$ & $\checkmark$ & $\checkmark$ & $x$ \\
\hline & Entropy index $(H)$ & $x$ & $\checkmark$ & $\checkmark$ & $\boldsymbol{V}$ & $\checkmark$ & $\checkmark$ & $\checkmark$ \\
\hline & Gini index $(\mathrm{G})$ & $x$ & $\checkmark$ & $\checkmark$ & $\checkmark$ & $\checkmark$ & $\checkmark$ & $\checkmark$ \\
\hline & Atkinson index $(0.1),(0.5),(0.9)$ & $x$ & $\checkmark$ & $x$ & $x$ & $\checkmark$ & $\checkmark$ & $\checkmark$ \\
\hline \multirow[t]{3}{*}{ Exposure } & Isolation index $(x P x)$ & $x$ & $\boldsymbol{\nu}$ & $\times$ & $x$ & $\checkmark$ & $\checkmark$ & $\boldsymbol{V}$ \\
\hline & Interaction index $(x P y)$ & $x$ & $x$ & $\boldsymbol{\sim}$ & $x$ & $\checkmark$ & $\checkmark$ & $\boldsymbol{V}$ \\
\hline & Correlation ratio $\left(E t a^{2}\right)$ & $x$ & $\checkmark$ & $x$ & $x$ & $\checkmark$ & $\checkmark$ & $\checkmark$ \\
\hline Clustering & Spatial proximity index $(S P)$ & $\checkmark$ & $\times$ & $\checkmark$ & $\checkmark$ & $\checkmark$ & $\checkmark$ & $x$ \\
\hline \multirow[t]{2}{*}{ Concentration } & Delta index $(D E L)$ & $\boldsymbol{\sim}$ & $\checkmark$ & $\checkmark$ & $x$ & $\checkmark$ & $\checkmark$ & $x$ \\
\hline & Index of relative concentration $(R C O)$ & $\checkmark$ & $x$ & $\boldsymbol{\sim}$ & $x$ & $\checkmark$ & $\boldsymbol{V}$ & $\checkmark$ \\
\hline \multirow[t]{2}{*}{ Local indices } & Location quotient $(Q L)$ & $\boldsymbol{\sim}$ & - & - & - & $\checkmark$ & $\checkmark$ & $\checkmark$ \\
\hline & Entropy $(H 2)$ & $\boldsymbol{\sim}$ & - & - & - & $\checkmark$ & $\checkmark$ & $\boldsymbol{v}$ \\
\hline
\end{tabular}

( $p=0.05)$, which indicates that young adults with high scores reside near to other young adults who report high scores in the CI. In contrast, the urban districts of Santafe, San Cristobal, Antonio Narino and Rafael Uribe Uribe cluster disadvantaged young adults in terms of capability achievement $(p=0.05)$.

The rest of the urban districts obtained capability scores that are significantly different from neither their neighbouring urban districts, nor from all the districts in Bogota. At this level, observations suggest that there is no significant evidence of processes of microsegregation in terms of capabilities. Negative autocorrelation (presence of outliers) was not found in the results, suggesting a high level of homogeneity within urban districts (Table 3).
On the side of UPZs, spatial clustering is also significant. Moran's $I$ for local spatial autocorrelation at this level was $0.373, p=0.001, n=98$. As expected, the Moran's I for capability scores shows a spatial autocorrelation similar to a fragmented city. At this level, an autocorrelation test points to the existence of two local 'hotspots' of high capability values in the western part ( 2 UPZs) and the northeastern part (12 UPZs) of the city $(p=0.05)$. The northern hotspot constitutes traditional areas that advantaged households tend to inhabit in Bogota.

There is just one cluster of low values ('coldspot'), but it is quite large in area. This cluster is composed of 18 UPZs and is located in the south-eastern part of the city. Geographic distance between young adults with 


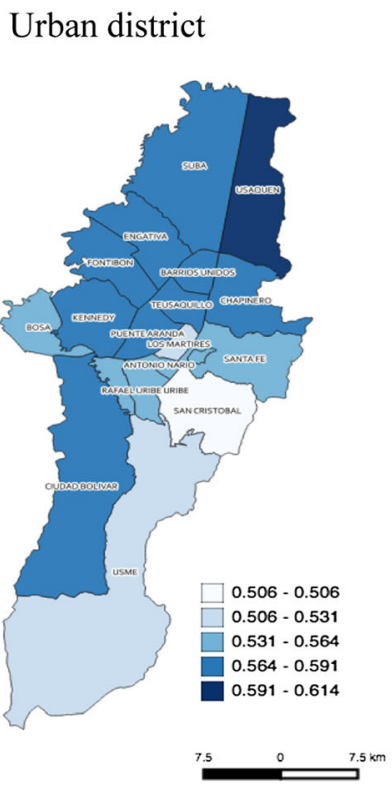

UPZ

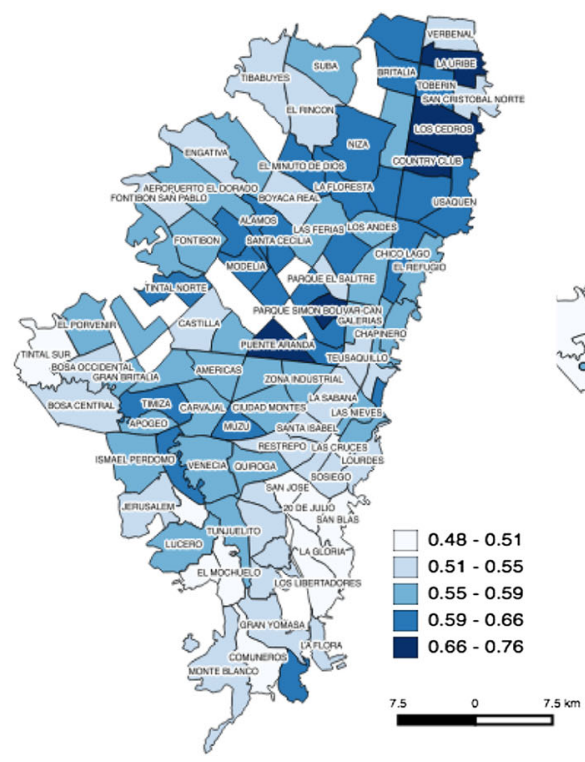

Blocks

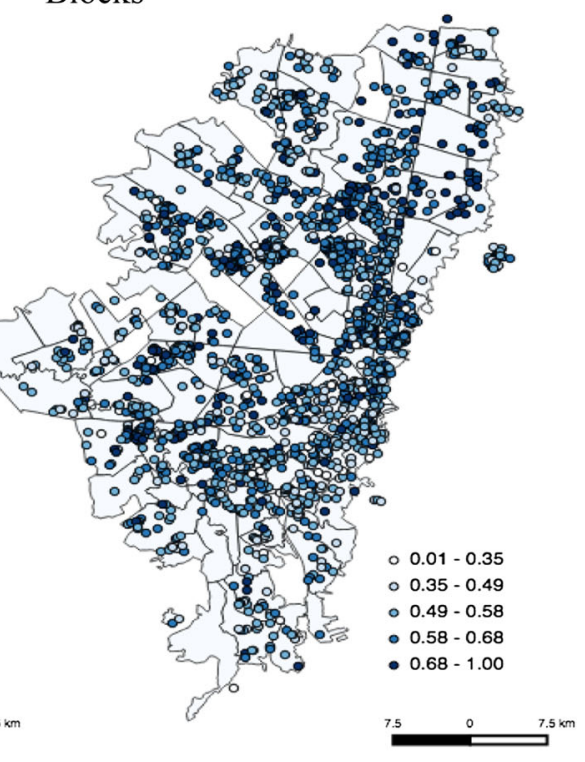

Fig. 2 Capability index by natural breaks (Jenks) (five classes). Note The distributions of the capability index in the different maps are not intended to be comparable as they use different areal units and natural class breaks, which use data-specific classifications
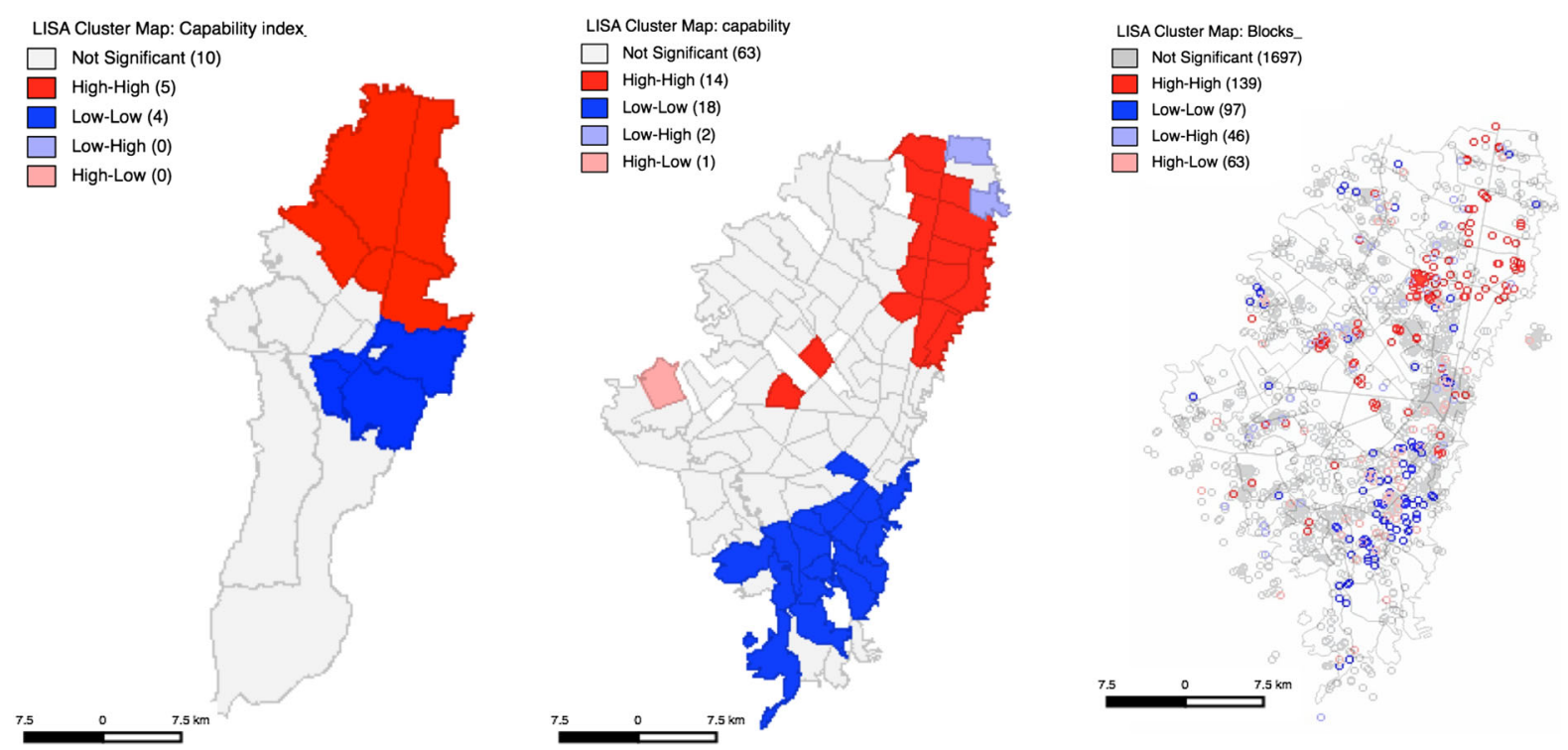

Fig. 3 LISA indicators by urban district, UPZ and block level. Note $p<0.05,999$ permutation. Census tracts with no significant spatial autocorrelation are left in grey

better and worse levels of capabilities continues to be marked in this scale. Interestingly, at this scale two additional zones show some negative autocorrelation (spatial outliers). On the north-eastern part of the city, close to the periurban zone, two UPZs (San Cristobal
Norte, $p=0.001$; and Verbenal, $p=0.05$ ) constitute poverty pockets in terms of capabilities. On the other hand, an 'isolated oasis' of high capabilities is present in the western side of the city. The UPZ of 'El Porvenir' presents significant high scores on the CI 
Table 3 Significant clusters for the capability index (urban district level)

\begin{tabular}{llll}
\hline $\begin{array}{l}\text { Cluster of low capabilities } \\
\text { Low-low (LL) } \\
\text { Blue }\end{array}$ & $\begin{array}{l}\text { Poverty pockets } \\
\text { Low-high (LH) } \\
\text { Light blue }\end{array}$ & $\begin{array}{l}\text { Isolated oasis } \\
\text { High-low (HL) } \\
\text { Pink }\end{array}$ & $\begin{array}{l}\text { Clusters of high capabilities } \\
\text { High-high (HH) } \\
\text { Red }\end{array}$ \\
\hline $\begin{array}{l}\text { Antonio Narino** } \\
\text { Rafael Uribe Uribe } * * *\end{array}$ & - & - & $\begin{array}{l}\text { Barrios Unidos** } \\
\text { Chapinero** } \\
\text { San Cristobal*** }\end{array}$ \\
Santa Fe** & & Engativa** \\
& & Suba** \\
& & Usaquen** \\
\hline
\end{tabular}

$* * * p<0.01 ; * * p<0.05$ $* p<0.1$ $(p=0.05)$ compared to its neighbouring peers, suggesting an unsynchronised development between capability achievement in this UPZ and neighbouring UPZ. Domains of the CI follow similar spatial patterns to the aggregated capability score (Table 4).

Using a more fine-grained scale of visualisation analysis, cases of separation and interaction between groups can be better identified. At block level, Moran's $I$ indicates a significant positive autocorrelation $(0.0929, p=0.001, n=2042) .{ }^{17}$ The univariate LISA analysis showed that two areas of hotspots are located in the north-western part of the city (Nuevo Monterrey, Potosi, Pasadena, Puente Largo, Santa Rosa and Los Andes) and in the north-eastern part (Bella Suiza) $(p=0.05)$. For coldspots, visualisation analysis showed a cluster in the south-eastern part of the city. Unlike visualisation analysis at urban district and UPZ level, patterns of interaction between groups are identified at the block level. In total nine 'poverty pockets' of capabilities and eight 'isolated oases' of capabilities were identified. Visualisation at the block level identified dissimilarity trends of high-low (weak read) areas $(p=0.01)$ in the urban districts of Los Martires (Santa Isabel), San Cristobal (Villa Javier and San Isidro), Chapinero (Granada and Juan XXIII), Barrios Unidos (la Castellana), and Engativa (Normandia). Conversely, dissimilarity trends of low-high (blue) values were identified in the urban districts of

\footnotetext{
${ }^{17}$ LISA indicators were calculated at the block level using two different weights (contiguity and $k$-nearest) and using visualisation by points and polygon units. Different weights and the visualisation analysis were conducted to evaluate the robustness of results.
}

La Candelaria (Las Aguas), Teusaquillo (La Soledad), Chapinero (Granada, Marly, Villa del Cerro), Fontibon (Modelia) and Engativa (Normandia).

At the address level, Moran's I remains positive but with a lower degree of autocorrelation (0.04, $p=0.001, n=7754)$. When LISA indicators for capability scores and socioeconomic stratification data are compared, the level and location of significance dependence differentiates between both variables. Moran's $I$ for strata is positive and significant (0.276, $p=0.001, n=7754)$ and higher than reported for capability scores, suggesting that clustering is more acute in terms of socioeconomic strata than capabilities. Generally, clustering by strata is higher in lower strata (1, 2, 3 and 4) and lower in higher strata (5 and 6) (Fig. 4).

The LISA analysis identified different high-risk areas of capability deprivation among young adults if domains of the index are taken into account (only at UPZ level). Figure 5 shows the spatial distribution of each domain of the CI in terms of significant concentration of high and low values of scores. Some interesting conclusions can be drawn from this analysis. First, values of high-low and low-high were more regular in the patterning at lower scales, implying spatial inequality in capability scores. At the same time, this patterning also suggests the existence of mixed communities in term of capabilities across the city landscape, weakening the north-south polarisation argument. Second, significant inequalities are portrayed in the domains of 'body integrity' and 'right of education' in comparison to other domains, as areas with low-high patterning cluster close to hotspots. Interestingly, 'right of education' also shows 
Table 4 Significant clusters and outliers for the capability index (UPZ level)

\begin{tabular}{|c|c|c|c|}
\hline $\begin{array}{l}\text { Cluster of low capabilities } \\
\text { Low-low (LL) } \\
\text { Blue }\end{array}$ & $\begin{array}{l}\text { Poverty pockets } \\
\text { Low-high }(\mathrm{LH}) \\
\text { Light blue }\end{array}$ & $\begin{array}{l}\text { Isolated oasis } \\
\text { High-low (HL) } \\
\text { Pink }\end{array}$ & $\begin{array}{l}\text { Clusters of high capabilities } \\
\text { High-high }(\mathrm{HH}) \\
\text { Red }\end{array}$ \\
\hline 20 de Julio*** & San Cristóbal Norte*** & El Porvenir & Bavaria \\
\hline Ciudad Jardin $* * *$ & Verbenal $* * *$ & & Britalia*** \\
\hline Danubio & & & Chico Lago \\
\hline Diana Turbay*** & & & Ciudad Salitre Occidental $* * *$ \\
\hline El Mochuelo & & & Country Club*** \\
\hline Gran Yamosa & & & El Prado*** \\
\hline La Gloria*** & & & El Refugio \\
\hline Las Cruces & & & La Alambra*** \\
\hline Los Libertadores & & & Los Andes \\
\hline Lourdes & & & Los Cedros \\
\hline Lucero*** & & & San Jose de Bavaria \\
\hline Marco Fidel Suarez & & & Santa Bárbara*** \\
\hline Marruecos & & & Toberin \\
\hline Monte Blanco*** & & & Usaquen*** \\
\hline \multicolumn{4}{|l|}{ San Blas*** } \\
\hline \multicolumn{4}{|l|}{ San Jose } \\
\hline \multicolumn{4}{|l|}{ Sosiego $* * *$} \\
\hline Tunjuelito*** & & & \\
\hline
\end{tabular}

$* * * p<0.01 ; * * p<0.05 ; * p<0.1$

a catching up process as there is evidence of high low values in common coldspots. Third, young adults who report better scores in terms of habitat and built environment, leadership and participation, occupation, and health and life are located in areas where on average there are worse capability scores (Fig. 5). Moreover, results of the spatialised CI follow patterning that is not income-driven, implying new pathways for young adult intervention. And fourth, non-significant clustering appears mainly in the western part of the city, suggesting a smooth capability patterning of the city which means that young adults in those areas have more similar capabilities.

\section{Regression models}

A spatial regression analysis was conducted to investigate how spatial dependence affects CI scores. The OLS regression model was tested by non-spatial regression diagnostics such as multicollinearity condition number (10.233) and the Jarque-Bera test statistics for normality of the errors $(p<0.001)$. A diagnostic for spatial effects was calculated by using a spatial weight file on the OLS regression. Specification checks were performed to ensure using a correct spatial model. First, the Lagrange Multiplier (LM) statistics for lag $(\rho)$ and error $(\lambda)$ terms were significant $(p<0.001)$, rejecting the null hypothesis of no spatial autocorrelation and requiring for testing robust LM statistics. The robust LM (lag) obtained a $p=0.039$ and the robust LM (error) becomes no longer significant $(p<0.84)$, suggesting spatial lag alternative as the most appropriate model to retain. ${ }^{18}$ In the regression, Moran's $I$ test is highly significant $(p<0.001)$, suggesting that we can reject the null hypothesis of no spatial autocorrelation (Anselin and Rey 2014).

Following the decision rule by Anselin and Rey (2014), a spatial lag model is estimated to control for

\footnotetext{
$\overline{18}$ This specification can be interpreted as the best way of controlling for spatial dependence of capability scores since a given young adult's capability score is related not only to its own starting level of quality of life, but also through the level of capability that other neighbouring young adults have.
} 

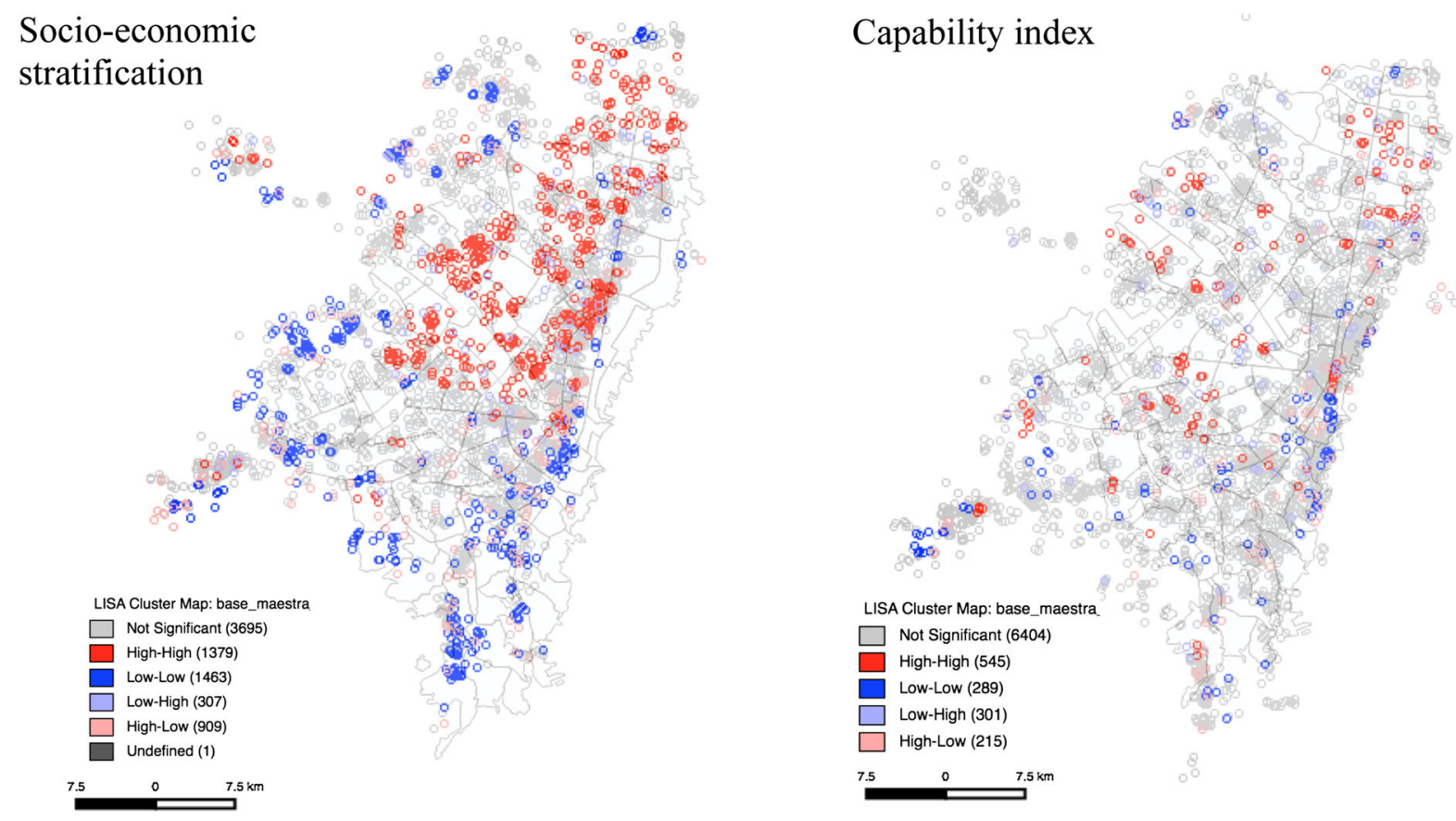

Fig. 4 LISA indicators for strata and CI scores at address level. Note $p<0.05,999$ permutation. Census tracts with no significant spatial autocorrelation are left in grey

spatial dependency. The description of the SAR model is:

$C I_{i}=\beta_{0}+\rho W C I+\beta_{1} \alpha_{i}+\beta_{2} \theta_{i}+\beta_{3} \vartheta_{i}+\beta_{4} \mu_{i}+\beta_{5} \eta_{i}+u$ a marginally higher value for R-square and $\log$ likelihood, and a smaller value report for AIC, where $\rho$ is the spatial autoregressive parameter, $W C I$ is the weights matrix or $n \times n$ spatial lag operator for $C I$, $\beta_{0} \sim \beta_{5}$ are the coefficients with the explanatory variables, and $u$ is the error term of individual $i$. The spatial autoregressive (SAR) model was conducted confirming the presence of spatial dependence as the spatial autoregressive coefficient is statistically significant $(\rho=0.12, p<0.01)$. A SAR model points out the relevance of the spatial component in the capability approach. In theoretical terms, the spatial dimension suggests that capability scores at specific areal units are related to scores in neighbouring areal units.

Another test for spatial dependence, the likelihood radio test, is also statistically significant ( $\mathrm{LR}=251$, $p<0.01$ ) which confirms strong evidence of spatial autocorrelation in the residuals. As a result, the general fit of the model improved using a SAR model. There is suggesting a better fit. Coefficients for independent variables in the lag model remain virtually the same as the OLS.

The lag variable (Rho) coefficient parameter that reflects the spatial dependence inherent in the data, confirms a positive correlation between the scores of the $\mathrm{CI}$ and neighbouring observations. Young adults without secondary education is negative and highly statistically significant, meaning that capability scores are lower in areas with lower educational attainment. In the same direction, deprived neighbourhoods are associated with lower capability scores (Table 5).

Conversely, estimates for gender (male), ethnicity (mestizo) and higher strata are significant and positive. As such, being male and mestizo and living in areas with higher strata increases the capability scores for young adults in Bogota. It is important to mention here 
Fig. 5 Cluster and significance maps for each domain of the capability index. Note All figures are mapped at $p=0.05$ on significant maps. The significance map shows the locations with a significant local statistic, with the degree of significance reflected in increasingly darker shades of green. (Color figure online)
1. Body integrity $(I=.4992)$
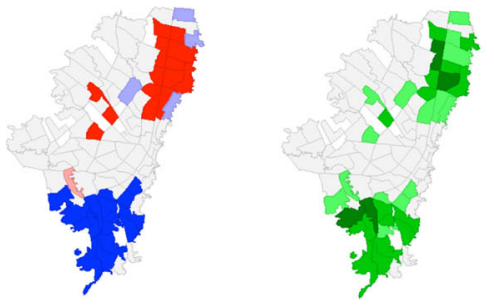

2. Habitat/built environment $(I=.230)$
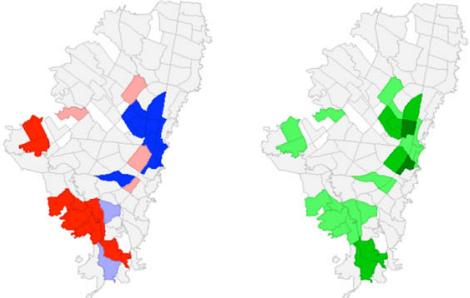

3. Freedom and independence $(I=.326)$
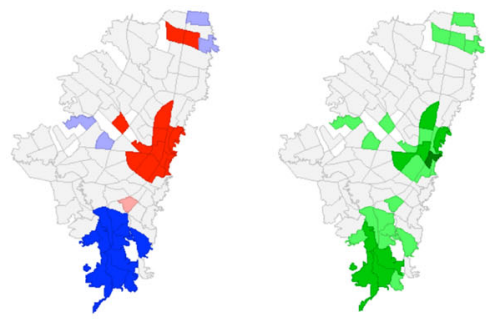

4. Occupation $(I=.131)$
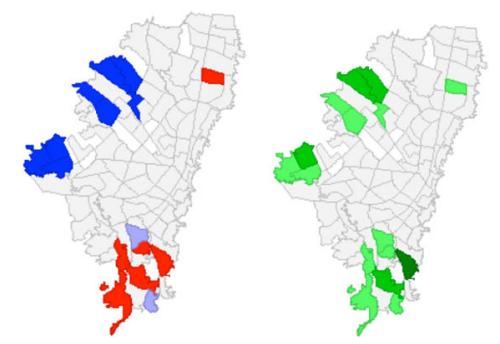

5. Food security $(I=.203)$
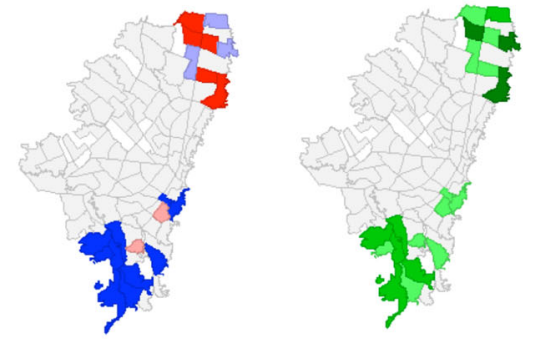

Equality/non-discrimination $(I=.046)$
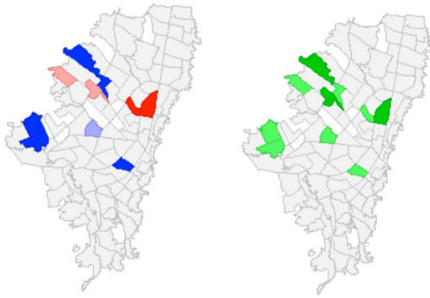

6. Right of education $(I=.068)$
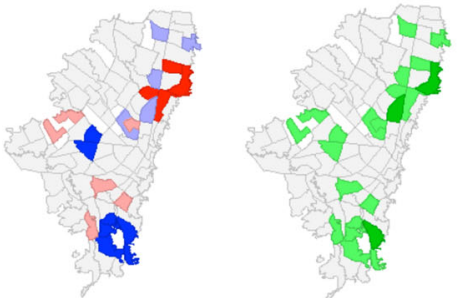

7. Leadership/participation $(I=-.017)$
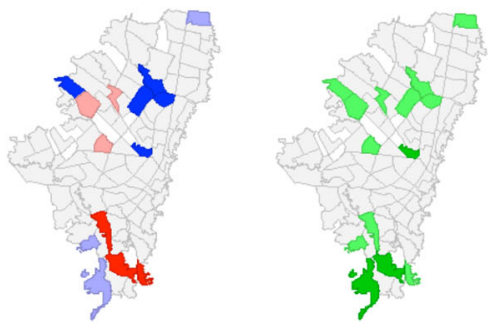

8. Love/support/affection $(I=.012)$
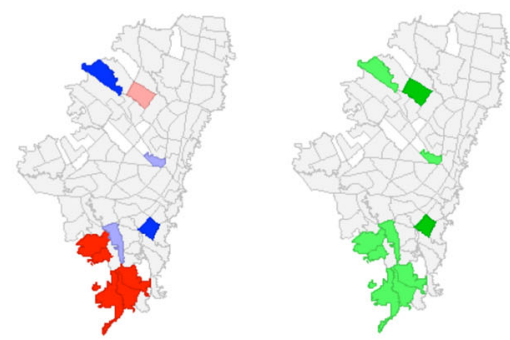

9. Health and life $(I=.130)$
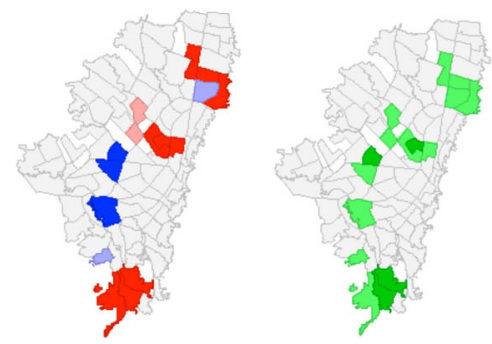

that although the SAR model has improved the model fit, the spatial effects are not completely controlled by the model. However, we can still argue that for capabilities, space matters. The lag model yielded improvement to the classical regression model, which means that controlling spatial dependence (spatial autocorrelation) can effectively improve the model performance. In other words, when spatial weights are 
Table 5 Comparison OLS and spatial regression (SAR model) results

\begin{tabular}{|c|c|c|c|c|}
\hline \multirow[t]{2}{*}{ Variable } & \multicolumn{2}{|c|}{ Multiple linear regression (OLS) } & \multicolumn{2}{|l|}{ SAR model } \\
\hline & Coefficients & $t$ value & Coefficient & $z$ value \\
\hline Stratum $(1-6)$ & $0.0384774 *$ & 14.0804 & 0.036355 & $13.2582 *$ \\
\hline Ethnicity & $0.0100019 *$ & 3.55998 & 0.00980364 & $3.50043 *$ \\
\hline Gender & $0.0125682 *$ & 4.48196 & 0.0125431 & $4.48722 *$ \\
\hline Poverty & $-0.0991185^{*}$ & -34.878 & -0.0987704 & $-34.8553 *$ \\
\hline Education & $-0.011191 *$ & -3.88444 & -0.0109349 & $-3.8073 *$ \\
\hline Adjusted R2 & 0.174905 & & 0.180020 & \\
\hline Rho $(\rho)^{\mathrm{a}}$ & & & 0.126099 & $5.50834 *$ \\
\hline Log likelihood & 5224.22 & & 5349.81 & \\
\hline Akaike criterion & $-10,436.4$ & & $-10,685.6$ & \\
\hline Schwarz criterion & $-10,394.7$ & & $-10,637$ & \\
\hline Moran $I$ (residual spatial autocorrelation & $0.0279 *$ & 5.7164 & & \\
\hline
\end{tabular}

*Significance at $p<0.001$

${ }^{\mathrm{a}}$ Spatial autoregressive coefficient

considered in the model, the spatial regression becomes more capable of predicting the CI than using a classical OLS regression (Stieve 2012).

\section{Segregation measurements}

Results are based on the proposed domains for measuring residential segregation by Massey and Denton (1988). Tables 9 and 10 show indices results for the dimensions of evenness, exposure, concentration and clustering. ${ }^{19}$ Segregation by capabilities can expand the informational base of urban poverty as its multidimensional nature captures the degree of spatial inequality embedded in the urban space of Bogota.

\section{Evenness}

The dissimilarity index $(D)$ shows that young adults who obtained very low $(D=0.67)$ and very high $(D=0.54)$ scores in terms of capabilities are those who are more segregated and underrepresented in Bogota. These two groups are less likely to be evenly spread across the whole city, showing a tendency of patterning between those who obtained lower and higher capability scores. At the urban district and UPZ

\footnotetext{
19 The domain of centralisation was not considered as Bogota has a polycentric urban structure, where other areas in the city rather than the traditional CBD (city's historical centre), are able to influence land prices and population of cities.
}

level, the patterning of underrepresentation of these groups is also present but in a lower degree than in the block scale. Nevertheless, for low $(D=0.50)$, medium $(D=0.43)$ and high $(D=0.43)$ score groups segregation is medium and for the groups in the extremes segregation is high, ${ }^{20}$ revealing a medium-high level of residential segregation of capabilities in young adults in Bogota (multigroup $D=0.48$ ). By comparing levels of segregation in terms of strata and capabilities, the former shows a much higher intensity in each group, suggesting that in Bogota, young adults are more segregated by strata than by capabilities. Figure 6 shows the local index of location quotient $(L Q)$ which illustrates the degree of underrepresentation $(L Q<1)$ and overrepresentation $(L Q>1)$ of capability groups at a UPZ level.

Figure 6 shows a clear underrepresentation of low scores of capabilities in the north-eastern part of the city, places where young adults with better rankings tend to be located. Geographic distance is also presented among young adults with low and high values, but to less extent in young adults with middle values of capabilities.

\footnotetext{
${ }^{20}$ In residential segregation literature a common rule of thumb to assess the level of intensity on segregation is that the dissimilarity is high for scores above $60 \%$, medium for scores between 30 and $60 \%$ and low for scores under $30 \%$ (Iceland et al. 2014).
} 
Fig. 6 Spatial distribution of capability scores using location quotient (LQ). Note $L Q<1$, indicates underrepresentation; $L Q>1$, indicates overrepresentation
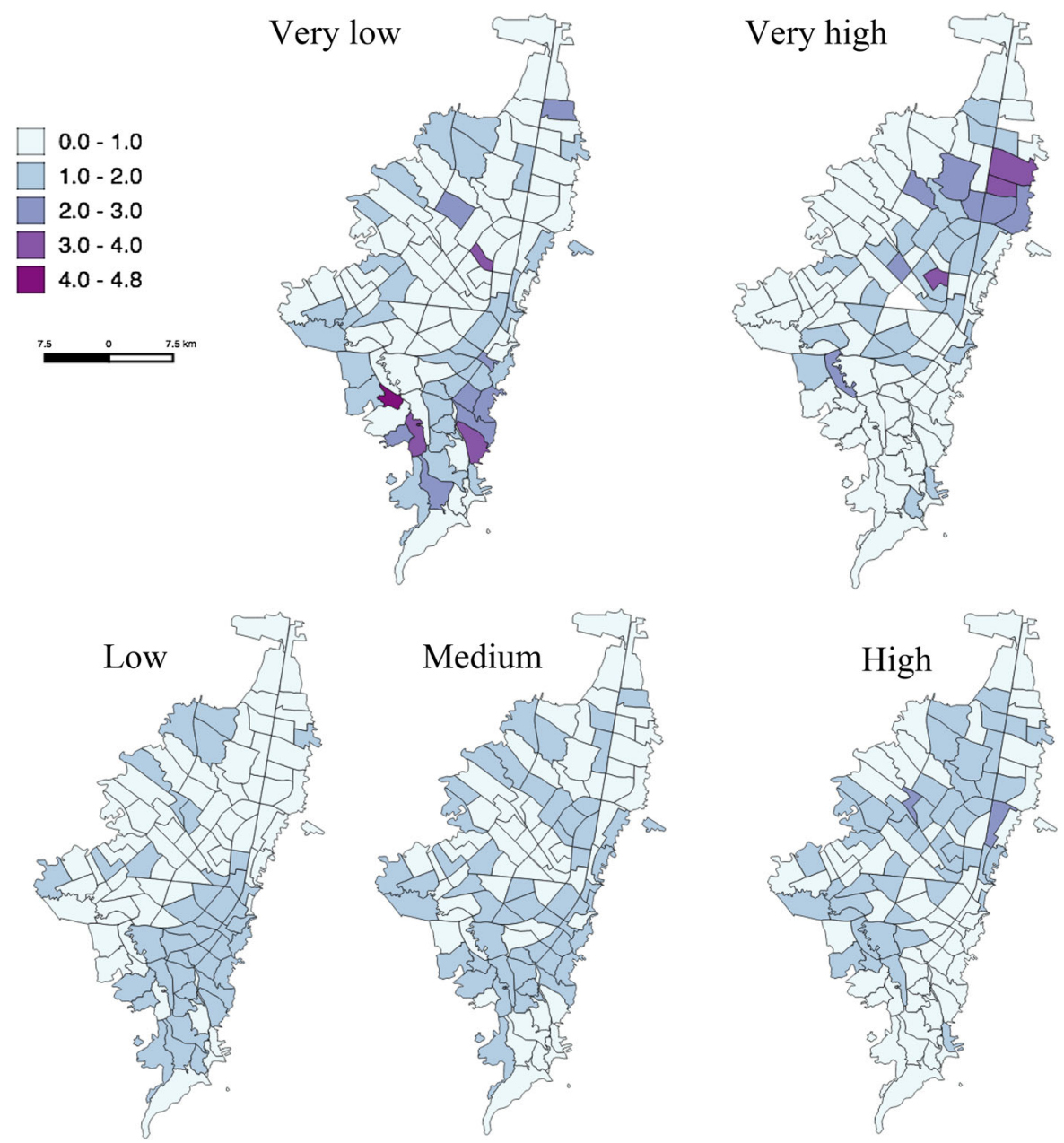

Figure 7 shows degrees of diversity across Bogota using local $H$. A visual inspection indicates that diversity tends to be more prominent that homogeneity, however it calls to attention the existence of 'mono-capabilist' spaces in the north-eastern, central and north-western parts of the city. By contrast, a corridor of 'multi-capabilist' spaces is located in the central part of the city, starting on the south-western side of the San Cristobal urban district and extending to the north in the urban districts of Chapinero and Barrios Unidos. Looking at $H$ and $D$ in its one-group version, levels of diversity and exposure are much higher than the equal distribution among groups (dissimilarity).

\section{Exposure}

For this domain, indices of isolation $\left({ }_{x} P_{x}\right)$ and interaction $\left({ }_{x} P_{y}\right)$ were calculated. ${ }_{x} P_{x}$ shows that the group of young adults with 'very high' capability scores has the least probability of meeting other groups of young adults. They have the highest probability $(47 \%)$ of meeting members of their own group rather than other groups. It has also been observed that the isolation index gradually declines as capability scores are reduced between groups. As ${ }_{x} P_{x}$ and ${ }_{x} P_{y}$ are asymmetric indices the chances of meeting varies among groups. Table 6 shows the different possible chances of meeting for each group. The chances of interaction for young adults with 'very low' capabilities are notoriously low in comparison with chances of meeting other groups. Exchanges of interaction tend to be more equitable from 'low' to 
Fig. 7 Diversity by capability scores and socioeconomic strata. Note The entropy index varies from 0 (totally homogeneous) to 1.0 (totally heterogeneous)
Table 6 Pairwise interaction index (xPy) for the capability index
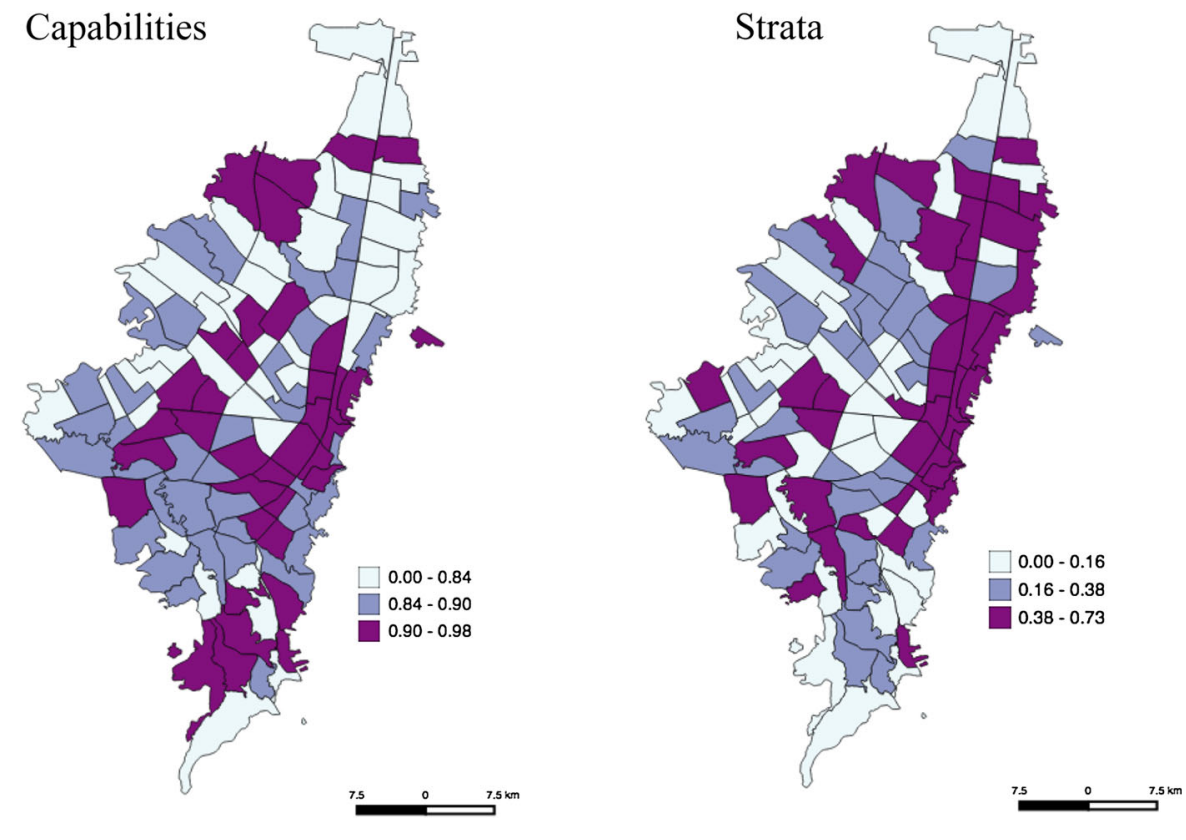

\begin{tabular}{llllll}
\hline & Very low $(\%)$ & Low $(\%)$ & Medium $(\%)$ & High $(\%)$ & Very high $(\%)$ \\
\hline Very low & - & 16 & 22 & 19 & 12 \\
Low & 5 & - & 22 & 19 & 13 \\
Medium & 4 & 14 & - & 19 & 14 \\
High & 4 & 12 & 20 & - & 16 \\
Very high & 3 & 11 & 18 & 20 & - \\
\hline
\end{tabular}

'very high' groups, and much less equitable for young adults with 'very low' capability scores. ${ }^{21}$

\section{Concentration}

Results from the delta index $(D E L)$ and the absolute concentration index (ACO) show that the degree of concentration among groups is moderate at the UPZ level. In relative terms, young adults with a very low level of capability scores are those who are more concentrated in Bogota $(D E L=0.44, A C O=0.57)$, meaning that $44 \%$ of young adults with very low scores would have to move to achieve uniform density. Similar results are shown at district level, showing dispersion among capability score results. For the case of block level, the relative concentration index (RCO)

\footnotetext{
$\overline{21}$ Table 10 shows the correlation index $\left(\mathrm{Eta}^{2}\right)$ which controls for population composition so that the asymmetrical relation is removed. Eta ${ }^{2}$ shows that interaction tends to be moderate-low between all groups.
}

was calculated to assess the concentration of a given group based on how other groups are distributed (majority). RCO shows that there are no cases of equal concentration of groups as values are not close to 0 .

\section{Clustering}

Unlike other segregation measurements reviewed here, the spatial proximity (SP) index takes into account the spatial structure of how capabilities are distributed in the urban space (White 1986). ${ }^{22}$ At UPZ level, young adults that share 'high' and 'very high' scores of capabilities $(S P=0.9945)$ tend to be closer to each other whereas groups with lower capability scores tend to live nearby (Table 7). In other words,

\footnotetext{
$\overline{22}$ The index is greater than 1 when members live nearer to members of their own group and it is less than 1 when members of one group are located closer to members of the other group. In the case of values of 1 , there is no evidence of differential clustering between groups (White 1983).
} 
Table 7 Pairwise spatial proximity index (SP) for the capability index

\begin{tabular}{llllll}
\hline & Very low & Low & Medium & High & Very high \\
\hline Very low & & 1.0004 & 1.0075 & 1.0297 & 1.0615 \\
Low & 1.0004 & & 1.0045 & 1.0249 & 1.0465 \\
Medium & 1.0075 & 1.0045 & & 1.0096 & 1.0178 \\
High & 1.0297 & 1.0249 & 1.0096 & & 0.9945 \\
Very high & 1.0615 & 1.0465 & 1.0178 & 0.9945 & \\
\hline
\end{tabular}

there is evidence that young adults with lower capabilities tend to cluster separately in Bogota, while young adults with higher capabilities are likely to live or be closer to other young adults with high capability scores. In the same vein, evidence of clustering occurs across a significant portion of the capability spectrum ('very low', 'low' and 'medium' scores) however this happens in a context of low spatial concentration.

Finally, segregation indices were calculated to each component of the CI. Results showed that young adults are more segregated by factors associated with domains of 'protection and body integrity', 'habitat and built environment', 'freedom and independence' and 'occupation'. This finding suggests that these areas are the domains that segregate the most in Bogota. To a lesser extent, young adults segregate themselves for conditions related to the 'right of education', 'equality and non-discrimination' in the city and the capacity for 'leadership and participation' (Table 8).

\section{Discussion}

Urban poverty and inequality demonstrate a spatial representation. The way place is configured, ordered and administered has implications for how people achieve better quality of life standards. For the case of young adults in Bogota, quality of life is sensitive to the effects of place, showing that levels of achievement are not equally distributed for all of them. The distribution of capabilities presented here helps to understand a more active role of places in explaining quality of life variations. Place has relational effects on human advantage and needs be considered as equally important as compositional effects when assessing people's lives (Cummins et al. 2007).

The autocorrelation test, regression model and measurements of segregation show that in Bogota, the geographical distance that exists between advantaged and non-advantaged groups leads to differences in the levels they score in the CI, meaning that the achievement of capabilities in young adults is sensitive to theirs and their neighbours' location. As a summary of findings, three main issues can be pointed out. First, young adults with similar capability levels tend to live closer to one another, suggesting a clustering of capabilities in Bogota. Second, capability scores are intrinsically mediated by the place where those young adults are located. And third, geographic inequalities show that residential segregation, in all its possible domains, is more prominent for young adults with lower capability scores. More importantly, segregation is associated with lower levels of quality of life for disadvantaged young adults, while at the same time it seems to positively affects quality of life levels of the most advantaged young adults. This finding indicates that residential segregation tends to widen the levels of inequality based on capabilities among young adults.

From the perspective of patterning in capability segregation, results showed a process of microsegregation in terms of capabilities. Results of testing global and local autocorrelation for the CI showed that hotspots, 'high-high' areas, were mostly located in the northern part of the city, indicating a significant capability advantage compared to other zones in Bogota. In particular, the UPZ of Santa Barbara is statistically significant as a cluster of high capability scores. In contrast, coldspot areas were mostly located in the south-eastern part of the city, particularly the UPZ of Sociego, whose 'low-low' correlation type is most significant, implying that capability achievement tends to be relatively lower than in the rest of Bogota. Young adults with a low capability level are more likely to live in the urban districts of San Cristobal and Rafael Uribe. There are significant areas appropriate for capability-driven interventions. For instance, at UPZ level, nine high risk coldspots were identified with low capability scores in young adults $(p=0.01)$ and two significant low-high areas $(p=0.01)$. A capability place-based approach suggests policy 
Table 8 Multi-group indices D, G and $\mathrm{H}$ for components of the CI

\begin{tabular}{llllllllllll}
\hline Index & Strata & $(1)$ & $(2)$ & $(3)$ & $(4)$ & $(5)$ & $(6)$ & $(7)$ & $(8)$ & $(9)$ & $(10)$ \\
\hline$D$ & 0.66 & 0.52 & 0.48 & 0.48 & 0.47 & 0.45 & 0.44 & 0.45 & 0.46 & 0.45 & 0.45 \\
$G$ & 0.81 & 0.71 & 0.67 & 0.67 & 0.66 & 0.64 & 0.63 & 0.64 & 0.65 & 0.64 & 0.63 \\
$H$ & 0.50 & 0.39 & 0.34 & 0.34 & 0.34 & 0.32 & 0.33 & 0.33 & 0.33 & 0.32 & 0.32 \\
\hline
\end{tabular}

(1) Protection and body integrity, (2) habitat and built environment, (3) freedom and independence, (4) occupation, (5) food security, (6) equality and non-discrimination, (7) right of education, (8) leadership and participation, (9) love, support and affection, (10) health and life

intervention should focus in those areas. This result demonstrates that spatial inequality in terms of capabilities still follows a macrosegregation process, where better off households occupy septentrional locations in the city and worse off populations consolidate their social and cultural activities in southern parts of the city (Alfonso 2012).

By considering this spatial autocorrelation in a spatial regression model, the analysis identified that there is a significant relationship between the level of capability scores and the degree of deprivation among young adults. Results confirm the importance of considering the spatial structure of the data in the analysis, as the model improves its estimation if neighbouring relations are not ignored. Spatial relationships in the case of capability scores work as a confounding variable and not considering this will lead to erroneous conclusions about the relationship between deprivation and scores of capabilities.

For all segregation indices calculated, scores increased as a much finer-grained scale was used, validating the existence of MAUP. Score differences of $D$ for all groups at district and UPZ level are marginal or moderate in the intensity of segregation, suggesting that capability segregation is not so different between bigger areal units. Nevertheless, at block level segregation scores increase substantially. This finding suggests that segregation in capabilities follows a pattern of macrosegregation rather than microsegregation: high and low scores in capabilities tend to live apart from one another as segregation intensifies at within lower scale units. $D, H, G$ and $A$ provided evidence that segregation operates in terms of capabilities, and that young adults with very low and very high scores tend to be underrepresented in spatial units. A multi-group $D$ indicates that $48 \%$ of young adults would have to change location to allow a more equal capability patterning in Bogota.
The most segregated capability group is the one that includes young adults with lower scores. This group finds itself in a situation of 'hyper-segregation' (Massey and Denton 1989) as it scores the highest level of segregation in terms of evenness, exposure, concentration and clustering. Interestingly, the second most segregated group is the one that has the most advantaged young adults in terms of capacities. Sixty-seven per cent of young adults with very low capability scores would need to change their place of residence for there to be an equal distribution of the young adults' population in Bogota in term of capabilities. The high level of segregation between these two groups reveals that segregation is a political problem for the poor but not for the rich. Having a high level of segregation for young adults with high capabilities also reveals that the reality of segregation is wrongly documented and is often influenced by the social and political perception of inequalities that considers segregation as a "default" state of the disadvantaged population.

Young adults with average capabilities (medium scores) tend to be the least segregated group as they are more evenly distributed in the city. A greater number of less segregated young adults in terms of capabilities indicates a possible hypothesis that the city is experiencing a trend of upward mobility in terms of capabilities, however without panel data available it is not possible to describe the trend of this pattern. Although the ongoing patterning of segregation in capabilities suggests that a large proportion of young adults, with average capability indicators, tend to be distributed evenly in the urban space of Bogota, the fact that many young adults are not segregated hides a situation of severe inequality at the extremes of capability distribution, as young adults with very low and very high capabilities are those who are most isolated and segregated in the city.

As expected, interaction between capability groups is less likely to happen between dissimilar groups. 
This pattern is in tandem with strata segregation as groups tend to interact with closer groups. As Sabatini et al. (2012) note in the case of Chilean cities, disadvantaged populations have a higher disposition to social integration than other groups, although it is restricted in practice due to the lack of housing supply in heterogeneous areas. In more detailed analysis, dissimilarity values tend to be higher on those young adults with lower capability scores with the particularity that isolation tends to improve in relation to other groups. This tendency is reversed when capabilities are distributed by strata. In this latter case, young adults with lower scores tend to be distributed more evenly in the space but, at the same time, they are more isolated than other peers. This situation helps us to argue that the greater the level of capabilities, the higher the level of isolation among young adults in Bogota.

An important finding indicates that the association between segregation and quality of life generates different outcomes if scores of capabilities are considered. For instance, for worse off young adults, having a better quality of life is associated with lower levels of segregation, lower levels of isolation and higher levels of exposure and interaction with other groups. However, this rationale is reversed if better off young adults are taken into consideration. For them, quality of life is associated with contexts where levels of segregation and isolation are higher and when the degree of interaction and exposure is lower. Or, to put the point differently, segregation, whether dissimilarity or isolation is taken into account, might be negatively affecting quality of life among disadvantaged young adults and, at the same time, benefitting the most advantaged young adults. This rather contradictory result suggests that residential segregation might generate different effects on quality of life for young adults which complicates how policymakers approach the problem of residential segregation in Bogota. Further research is needed in this area to better understand better the causal relationship mediating between quality of life and segregation.

In term of the stratification policy in Bogota, differences of evenness and exposure are identified when comparing strata and capability segregation. Strata segregation shows higher levels of segregation in each domain compared with results of capability scores. As Aliaga and Álvarez (2010) identified previously by comparing strata with variables such as poverty and education, this study finds that strata segregation does not correspond to the patterning produced by capability segregation. This finding indicates that stratification policies should modify their targeting goals to efficiently tackle ongoing deficits of capability achievement among young adults in segregated areas of Bogota.

Quality of life based on capabilities can be more informative that other measurements of well-being. In our case, spatialising capabilities among young adults shows that domains have different trends across groups. LISA indicators showed that domains such as body integrity and right of education can be seen as sources of spatial inequality among young adults. This is also confirmed with measurements of segregation, as 'right of education' and 'non-discrimination', present almost perfect levels of segregation, suggesting they are the domains that segregate more young adults in Bogota. In addition to this, those young adults that tend to have a very low ability to receive quality education tend to be more segregated than other peers. In the same vein, young adults with very low scores in the domain of inclusion (feeling incorporated into society) are highly segregated in Bogota.

Results suggest that there is not one but multiple processes of segregation when spatial differentiation is based on capabilities, challenging the elaboration of public policy and the design of mechanisms that attempt to reduce socio-spatial inequalities in urban settings. These results suggest the potential for the wider application of spatial analysis in revealing patterns of residential segregation in well-being and agency data. Clustering of capabilities is informative to policymakers to develop contextually sensitive policy interventions that can alleviate spatial inequalities in Bogota.

Funding Funding for this study was provided by the Colciencias Cambridge Scholarship (Cambridge Commonwealth, European and International Trust).

\section{Compliance with ethical standards}

Conflict of interest The author declares that there is no conflict of interest with any financial organisations regarding the materials reported in this manuscript.

Open Access This article is distributed under the terms of the Creative Commons Attribution 4.0 International License (http:// creativecommons.org/licenses/by/4.0/), which permits unrestricted use, distribution, and reproduction in any medium, provided you give appropriate credit to the original author(s) and the source, provide a link to the Creative Commons license, and indicate if changes were made. 


\section{Appendix}

See Tables 9 and 10.

Table 9 Results of selected indices of segregation for evenness

\begin{tabular}{|c|c|c|c|c|c|c|c|c|c|c|c|c|c|c|c|}
\hline \multirow[t]{2}{*}{ Index } & \multicolumn{3}{|c|}{$\begin{array}{l}\text { Dissimilarity index } \\
(D)\end{array}$} & \multicolumn{3}{|c|}{$\begin{array}{l}\text { Dissimilarity index } \\
(D) \text { (multi-group) }\end{array}$} & \multicolumn{3}{|c|}{$\begin{array}{l}\mathrm{D} \text { adjusted tract } \\
\text { contiguity (adj) }\end{array}$} & \multicolumn{3}{|c|}{ Entropy index $(\mathrm{H})$} & \multicolumn{3}{|c|}{$\begin{array}{l}\text { Entropy index (multi- } \\
\text { group) }\end{array}$} \\
\hline & U1 & Up & B & Ul & Up & B & U1 & Up & B & U1 & Up & B & Ul & Up & B \\
\hline Very low & 0.160 & 0.248 & 0.680 & & & & 0.134 & 0.205 & $\mathrm{n} / \mathrm{a}$ & 0.021 & 0.053 & 0.387 & & & \\
\hline Low & 0.112 & 0.164 & 0.504 & & & & 0.077 & 0.104 & $\mathrm{n} / \mathrm{a}$ & 0.011 & 0.029 & 0.287 & & & \\
\hline Medium & 0.082 & 0.125 & 0.432 & 0.105 & 0.172 & 0.487 & 0.029 & 0.049 & $\mathrm{n} / \mathrm{a}$ & 0.007 & 0.018 & 0.230 & 0.016 & 0.045 & 0.351 \\
\hline High & 0.072 & 0.137 & 0.432 & & & & 0.031 & 0.059 & $\mathrm{n} / \mathrm{a}$ & 0.007 & 0.022 & 0.231 & & & \\
\hline Very high & 0.165 & 0.273 & 0.541 & & & & 0.118 & 0.164 & $\mathrm{n} / \mathrm{a}$ & 0.027 & 0.074 & 0.314 & & & \\
\hline \multirow[t]{2}{*}{ Index } & \multicolumn{3}{|c|}{ Gini index $(G)$} & \multicolumn{3}{|c|}{$\begin{array}{l}\text { Gini index (multi- } \\
\text { group) }\end{array}$} & \multicolumn{3}{|c|}{ Atkinson (0.1) } & \multicolumn{3}{|c|}{ Atkinson (0.5) } & \multicolumn{2}{|c|}{$\begin{array}{l}\text { Atkinson } \\
(0.9)\end{array}$} & \\
\hline & U1 & Up & B & U1 & Up & B & U1 & Up & B & U1 & Up & B & U1 & Up & $\mathrm{B}$ \\
\hline Very low & 0.217 & 0.344 & 0.829 & & & & 0.008 & 0.052 & 0.644 & 0.040 & 0.117 & 0.739 & 0.073 & 0.172 & 0.935 \\
\hline Low & 0.151 & 0.230 & 0.693 & & & & 0.004 & 0.019 & 0.416 & 0.018 & 0.051 & 0.551 & 0.033 & 0.079 & 0.893 \\
\hline Medium & 0.101 & 0.178 & 0.623 & 0.1450 & 0.241 & 0.673 & 0.002 & 0.006 & 0.314 & 0.009 & 0.026 & 0.474 & 0.017 & 0.046 & 0.901 \\
\hline High & 0.107 & 0.194 & 0.621 & & & & 0.002 & 0.010 & 0.321 & 0.011 & 0.035 & 0.475 & 0.018 & 0.058 & 0.900 \\
\hline Very high & 0.234 & 0.373 & 0.729 & & & & 0.010 & 0.034 & 0.427 & 0.047 & 0.120 & 0.580 & 0.080 & 0.212 & 0.911 \\
\hline
\end{tabular}

$U l$ urban district, $U p$ UPZ, $B$ block

Table 10 Results of selected indices of segregation for exposure, clustering and concentration

$U l$ urban district, $U p$ UPZ, $B$ block

\begin{tabular}{|c|c|c|c|c|c|c|c|c|c|c|}
\hline \multirow[t]{3}{*}{ Index } & \multicolumn{10}{|c|}{ Exposure } \\
\hline & \multicolumn{3}{|c|}{ Isolation index $(x P x)$} & \multicolumn{4}{|c|}{ Correlation ratio $\left(E t a^{2}\right)$} & \multicolumn{3}{|c|}{ Relative diversity (R) } \\
\hline & U1 & Up & B & U1 & & & B & Ul & Up & B \\
\hline Very low & 0.074 & 0.094 & 0.316 & 0.0 & & 026 & 0.274 & & & \\
\hline Low & 0.179 & 0.202 & 0.413 & 0.0 & & 025 & 0.287 & & & \\
\hline Medium & 0.319 & 0.342 & 0.483 & 0.0 & & 022 & 0.282 & 0.011 & 0.032 & 0.293 \\
\hline High & 0.320 & 0.275 & 0.472 & 0.0 & & 024 & 0.277 & & & \\
\hline Very high & 0.157 & 0.224 & 0.478 & 0.0 & & 071 & 0.334 & & & \\
\hline \multirow[t]{3}{*}{ Index } & \multicolumn{3}{|c|}{ Clustering } & \multicolumn{7}{|c|}{ Concentration } \\
\hline & \multicolumn{3}{|c|}{$\begin{array}{l}\text { Spatial proximity index } \\
(S P)\end{array}$} & \multicolumn{3}{|c|}{ Delta index $(D E L)$} & \multicolumn{4}{|c|}{$\begin{array}{l}\text { Index of relative concentration } \\
(R C O)\end{array}$} \\
\hline & Ul & Up & B & Ul & Up & B & U1 & Up & & B \\
\hline Very low & - & & - & 0.301 & 0.446 & 0.991 & - & - & & - \\
\hline Low & 0.999 & 1.000 & $\mathrm{n} / \mathrm{a}$ & 0.371 & 0.426 & 0.981 & -0.170 & 0.0 & & 0.114 \\
\hline Medium & 0.999 & 1.008 & $\mathrm{n} / \mathrm{a}$ & 0.366 & 0.395 & 0.971 & -0.272 & & 0.006 & 0.389 \\
\hline High & 0.998 & 1.030 & $\mathrm{n} / \mathrm{a}$ & 0.361 & 0.406 & 0.973 & -0.181 & & 0.013 & 0.443 \\
\hline Very high & 0.995 & 1.062 & $\mathrm{n} / \mathrm{a}$ & 0.355 & 0.441 & 0.979 & -0.107 & - & 0.007 & 0.385 \\
\hline
\end{tabular}




\section{References}

Abel, T., \& Frohlich, K. L. (2012). Capitals and capabilities: Linking structure and agency to reduce health inequalities. Social Science and Medicine, 74(2), 236-244. https://doi. org/10.1016/j.socscimed.2011.10.028.

Alfonso, O. (2012). Bogotá segmentada: Reconstrucción histórico-social de la estructuración residencial de una metrópoli latinoamericana. Bogotá: U. Externado de Colombia.

Aliaga, L., \& Álvarez, M. J. (2010). Residential segregation in Bogotá across time and scales. Cambridge: Lincoln Institute of Land Policy.

Alkire, S., \& Deneulin, S. (2009). A normative framework for development. In An introduction to the human development and capability approach: Freedom and agency. IDRC.

Anselin, L. (1995). Local indicators of spatial associationLISA. Geographical Analysis, 27(2), 93-115. https://doi. org/10.1111/j.1538-4632.1995.tb00338.x.

Anselin, L., \& Rey, S. J. (2014). Modern spatial econometrics in practice: A guide to GeoDa, GeoDaSpace and PySAL. Chicago, IL: GeoDa Press LLC.

Bucheli, J. F. (2018). Before entering adulthood: Measuring quality of life in young adults in Bogota. Manuscript submitted for publication. Applied Research in Quality of Life.

Burgess, R. (2007). Technological determinism and urban fragmentation: A critical analysis. Presented at the Proceedings of the 9th international conference of the ALFAIBIS Network on Urban Peripheries, Santiago de Chile: Pontificia Universidad Catolica de Chile. Retrieved from http://ccs.ukzn.ac.za/files/Burgess\%20against\% 20technological\%20determinism.pdf. Accessed 05 Oct 2018.

Casas-Casas, A., DNP, Colombia Joven, GIZ, OIM, \& USAID. (2012). Jóvenes constructores de política: Recomendaciones para la implementación de políticas de juventud. Retrieved from http://repository.oim.org.co/handle/20. 500.11788/408. Accessed 04 Oct 2018.

Castells, M. (1977). The urban question: A Marxist approach. Cambridge: MIT Press.

Castells, M. (2004). The power of identity (2nd ed.). Oxford: Blackwell.

Chi, G., \& Zhu, J. (2008). Spatial regression models for demographic analysis. Population Research and Policy Review, 27(1), 17-42.

Cummins, S., Curtis, S., Diez-Roux, A. V., \& Macintyre, S. (2007). Understanding and representing 'place' in health research: A relational approach. Social Science and Medicine, 65(9), 1825-1838. https://doi.org/10.1016/j.socscimed.2007. 05.036 .

Deneulin, S., \& Shahani, L. (Eds.). (2009). An introduction to the human development and capability approach: Freedom and agency. Sterling, VA: Routledge.

Dikeç, M. (2001). Justice and the spatial imagination. Environment and Planning A, 33(10), 1785-1805. https://doi. org/10.1068/a3467.

Econometria. (2018). Evaluación de la estratificación socioeconómica como instrumento de la clasificación de los usuarios y herramienta de asignación de subsidios y contribuciones a los servicios públicos domiciliarios.
Departamento Nacional de Planeacion, Ministerio de Hacienda y Credito Publico. Retrieved from https://www. dane.gov.co/files/geoestadistica/Evaluacion_

Estratificaicon.pdf. Accessed 17 Oct 2018.

Evans, B., Elisei, P., Rosenfeld, O., Roll, G., Figueiredo, A., \& Keiner, M. (2016). HABITAT III-Toward a new urban agenda. Disp-the Planning Review, 52(1), 86-91. https:// doi.org/10.1080/02513625.2016.1171053.

Fainstein, S. S. (2011). The just city. Ithaca: Cornell University Press.

Fukuda-Parr, S. (2011). Theory and policy in international development: Human development and capability approach and the millennium development goals. International Studies Review, 13(1), 122-132. https://doi.org/ 10.1111/j.1468-2486.2010.01003.x.

Gallego, J. M., López, D., \& Sepúlveda, C. (2014). Estratificación socioeconómica con base en información catastral. Modelos para el caso de Bogotá, D.C (DOCUMENTOS DE TRABAJO No. 012255). Universidad Del Rosario. Retrieved from https://ideas.repec.org/p/col/000092/ 012255.html. Accessed 17 Oct 2018.

Gasper, D. (2007). What is the capability approach? Its core, rationale, partners and dangers. The Journal of SocioEconomics, 36(3), 335-359. https://doi.org/10.1016/j. socec. 2006.12.001.

Giddens, A. (1990). The consequences of modernity. Stanford: Stanford University Press.

Good, P. I. (2010). Permutation, parametric, and bootstrap tests of hypotheses (Softcover reprint of hardcover 3rd ed. 2005 edition). New York: Springer.

Graham, S., \& Marvin, S. (2001). Splintering urbanism: Networked infrastructures, technological mobilities and the urban condition. New York: Routledge.

Haining, R., \& Amable, G. (2013). Practical 6: Regression analysis applied to spatial data. Cambridge: Department of Geography, University of Cambridge.

Haq, M. U. (1995). Reflections on human development. New York: Oxford University Press Inc.

Harvey, D. (1973). Social justice and the city. Baltimore: Johns Hopkins University Press.

Harvey, D. (2006). Spaces of global capitalism: Towards a theory of uneven geographical development. London: Verso Books.

Iceland, J., Weinberg, D., \& Hughes, L. (2014). The residential segregation of detailed Hispanic and Asian groups in the United States: 1980-2010. Demographic Research. https:// doi.org/10.4054/DemRes.2014.31.20.

Israel, E., \& Frenkel, A. (2017). Social justice and spatial inequality: Toward a conceptual framework. Progress in Human Geography. https://doi.org/10.1177/0309132 517702969.

Landman, K. (2011). Urban fragmentation: Different views on its causes and consequences. Edward Elgar Publishing. Retrieved from https://www.elgaronline.com/view/ 9781847204608.00009.xml. Accessed 05 Oct 2018.

Lemanski, C., \& Marx, C. (2015). Introduction. In The city in urban poverty. EADI global development series. New York: Palgrave Macmillan.

Marcuse, P., Connolly, J., Novy, J., Olivo, I., Potter, C., \& Steil, J. (Eds.). (2011). Searching for the just city: Debates in urban theory and practice (1st ed.). London: Routledge. 
Massey, D. (2009). Concepts of space and power in theory and in political practice. Documents d'anàlisi Geogràfica, (55), 15-26.

Massey, D. S., \& Denton, N. A. (1988). The dimensions of residential segregation. Social Forces, 67(2), 281-315.

Massey, D. S., \& Denton, N. A. (1989). Hypersegregation in U.S. metropolitan areas: Black and Hispanic segregation along five dimensions. Demography, 26(3), 373-391. https://doi.org/10.2307/2061599.

Merrifield, A. (1999). The extraordinary Voyages of Ed Soja: Inside the 'Trialectics of Spatiality'. Annals of the Association of American Geographers, 89(2), 345-348.

Merrifield, A., \& Swyngedouw, E. (1997). Social justice and the urban experience: An introduction. In The urbanization of injustice. Washington Square: New York University Press.

Olson, E., \& Sayer, A. (2009). Radical geography and its critical standpoints: Embracing the normative. Antipode, 41(1), 180-198. https://doi.org/10.1111/j.1467-8330.2008.00661.x.

Qizilbash, M. (2011). Sugden's critique of Sen's capability approach and the dangers of libertarian paternalism. International Review of Economics, 58(1), 21-42. https://doi. org/10.1007/s12232-011-0112-2.

Reardon, S. F., \& O’Sullivan, D. (2004). Measures of spatial segregation. Sociological Methodology, 34(1), 121-162. https://doi.org/10.1111/j.0081-1750.2004.00150.x.

Sabatini, F., Rasse, A., Mora, P., \& Brain, I. (2012). Es posible la integración residencial en las ciudades chilenas?: Disposición de los grupos medios y altos a la integración con grupos de extracción popular. EURE (Santiago), 38(115), 159-194. https://doi.org/10.4067/S0250-71612012000300008.

Sassen, S. (2013). The global city: New York, London, Tokyo. Princeton: Princeton University Press.

Satterthwaite, D. (2001). Reducing urban poverty: Constraints on the effectiveness of aid agencies and development banks and some suggestions for change. Environment and Urbanization, 13(1), 137-157. https://doi.org/10.1177/ 095624780101300111.

Sen, A. (1979). Equality of what? In The Tanner lecture on human values, I (pp. 197-220). Delivered at Stanford University.

Sen, A. (1985). Well-being, agency and freedom: The Dewey Lectures 1984. The Journal of Philosophy, 82(4), 169. https://doi.org/10.2307/2026184.

Sen, A. (1992). Inequality reexamined. Oxford: Oxford University Press.

Sen, A., \& Williams, B. (1982). Utilitarianism and beyond. Cambridge: Cambridge University Press.

Sepulveda, C., Lopez, D., \& Juan, G. (2014). The limits of socioeconomic stratification: In search of alternatives [Los limites de la estratificacion: En busca de alternativas]. Bogota: Universidad del Rosario.

Smith, M. J. D., Goodchild, M. F., \& Longley, P. (2015). Geospatial analysis: A comprehensive guide to principles, techniques and software tools (5th ed.). Leicester: Troubador Publishing Ltd.

Soja, E. W. (1999). Keeping space open. Annals of the Association of American Geographers, 89(2), 348-353. https:// doi.org/10.1111/0004-5608.00152.

Soja, E. (2009). The city and spatial justice. Justice Spatiale Spatial Justice, 1(1). Retrieved from http://www.jssj.org. Accessed 18 May 2018.

Soja, E. (2010). Seeking spatial justice. Minneapolis: University OF Minnesota Press.

Stewart, F., \& Deneulin, S. (2002). Amartya Sen's contribution to development thinking. Studies in Comparative International Development, 37(2), 61-70. https://doi.org/10. 1007/BF02686262.

Stieve, T. (2012). Moran's I and spatial regression. Retrieved from http://sites.tufts.edu/gis/files/2013/11/Morans-I-andSpatial-Regression.docx. Accessed 23 Aug 2017.

Thompson, R. (2017). Opportunity structures and educational marginality: The post-16 transitions of young people outside education and employment. Oxford Review of Education, 43(6), 749-766. https://doi.org/10.1080/03054985. 2017.1352502 .

Unwin, T. (2000). A waste of space? Towards a critique of the social production of space.... Transactions of the Institute of British Geographers, 25(1), 11-29.

Uribe, C., \& Pardo, C. (2006). La ciudad vivida: Movilidad espacial y representaciones sobre la estratificación social en Bogotá. Universitas Humanística. https://doi.org/10. $11144 / 2214$.

Voss, P. R., \& Chi, G. (2006). Highways and population change. Rural Sociology, 71(1), 33-58. https://doi.org/10.1526/ 003601106777789837.

White, M. J. (1983). The measurement of spatial segregation. American Journal of Sociology, 88(5), 1008-1018.

White, M. J. (1986). Segregation and diversity measures in population distribution. Population Index, 52(2), 198-221. https://doi.org/10.2307/3644339.

Wong, D. W. S. (1993). Spatial indices of segregation. Urban Studies, 30(3), 559-572. https://doi.org/10.1080/0042098 9320080551.

Wratten, E. (1995). Conceptualizing urban poverty. Environment and Urbanization, 7(1), 11-38. https://doi.org/10. $1177 / 095624789500700118$.

Young, I. M. (2011). Justice and the politics of difference (With a New foreword by Danielle Allen edition). Princeton, NJ: Princeton University Press.

Publisher's Note Springer Nature remains neutral with regard to jurisdictional claims in published maps and institutional affiliations. 